INTERNATIONAL MONETARY FUND

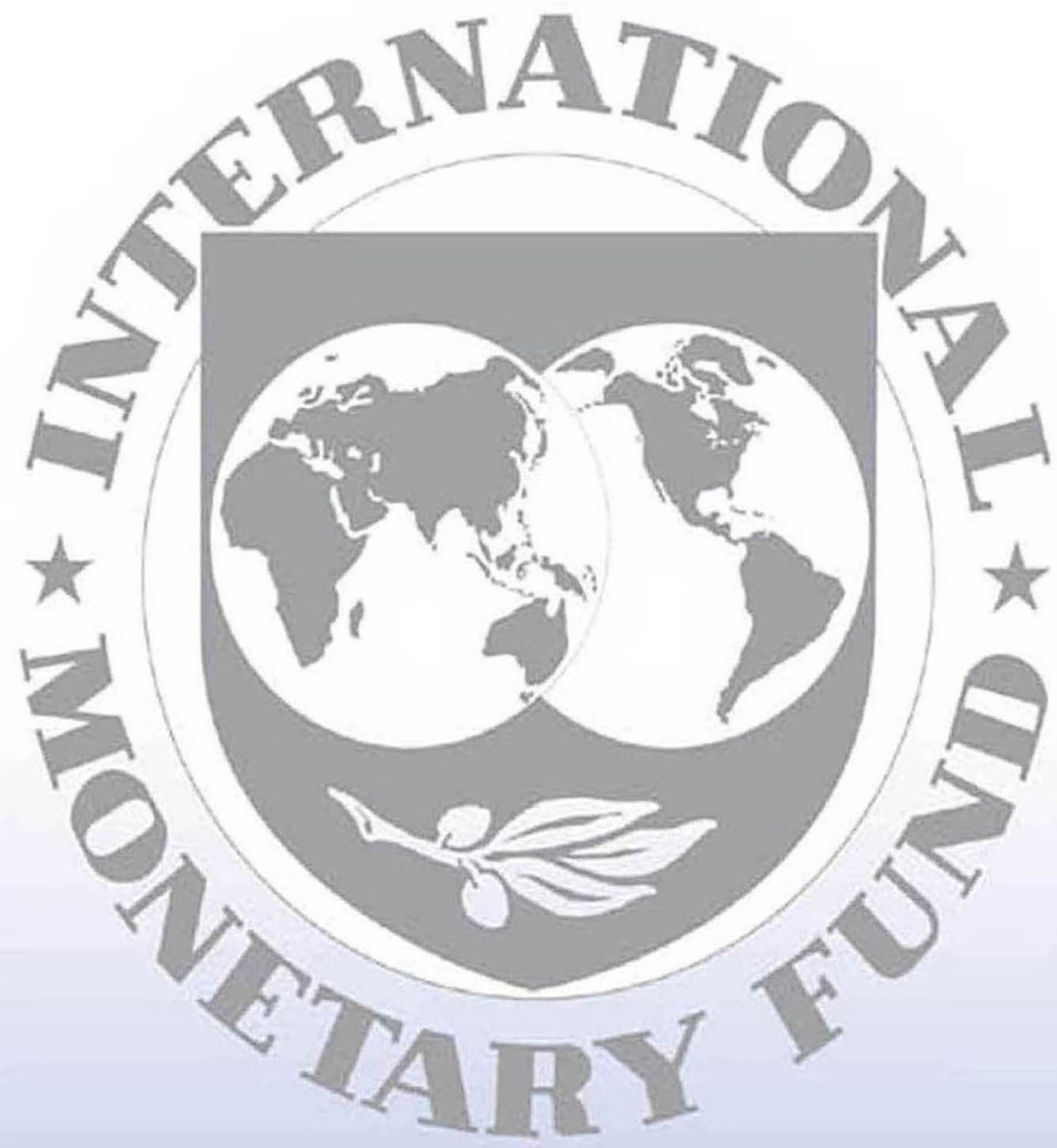

Staff

Country

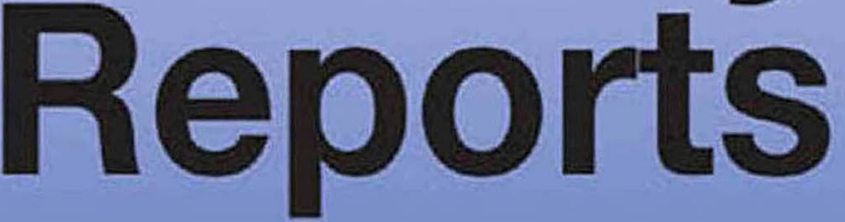




\title{
Republic of Poland: Selected Issues
}

This paper was prepared based on the information available at the time it was completed on June 14, 2012. The views expressed in this document are those of the staff team and do not necessarily reflect the views of the government of the Republic of Poland or the Executive Board of the IMF.

The policy of publication of staff reports and other documents allows for the deletion of market-sensitive information.

\author{
Copies of this report are available to the public from \\ International Monetary Fund $\bullet$ Publication Services \\ $70019^{\text {th }}$ Street, N.W. $\bullet$ Washington, D.C. 20431 \\ Telephone: (202) 623-7430 • Telefax: (202) 623-7201 \\ E-mail: publications@imf.org Internet: http://www.imf.org
}

\section{International Monetary Fund \\ Washington, D.C.}




\title{
INTERNATIONAL MONETARY FUND
}

\section{REPUBLIC OF POLAND}

\author{
Selected Issues \\ Prepared by Giang Ho and Yinqiu Lu (both EUR) \\ Approved by European Department
}

June 14,2012

Contents

I. Economic and Financial Linkages With the Euro Area …..............................................

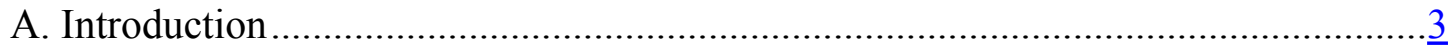

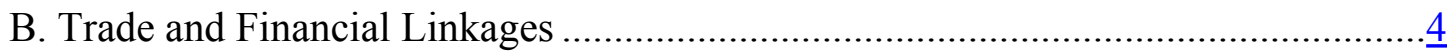

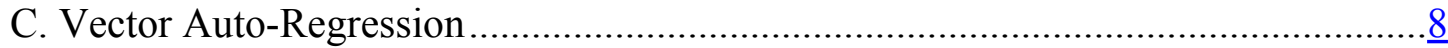

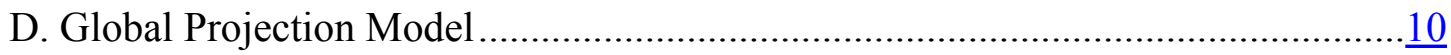

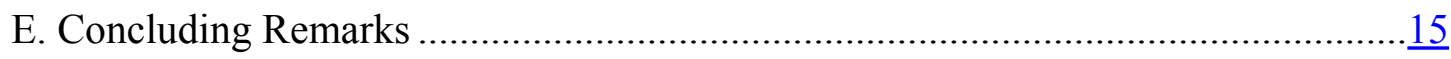

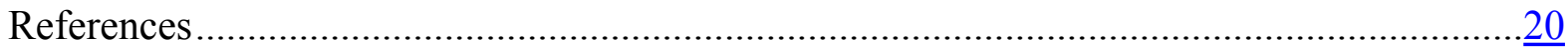

Box

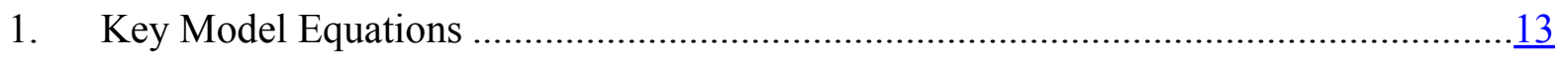

Figures

1. Responses to Euro Area Premium Shock ………......................................................

2. Responses to Euro Area Premium Shock With Anticipated Monetary Policy Delay …117

3. Responses to a More Persistent Euro Area Premium Shock ........................................18

4. Responses to Euro Area Premium Shock With Stronger Spillover ................................19

II. What Drives the Spread Between the POLONIA and the Policy Rate ...........................22

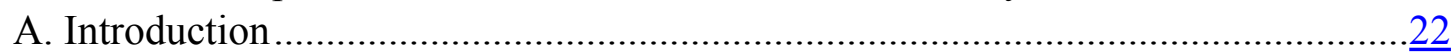

B. POLONIA and its Deviation From the Policy Rate .............................................23

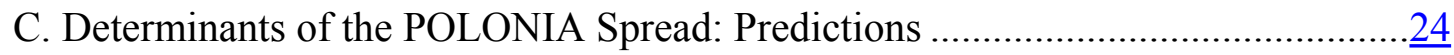

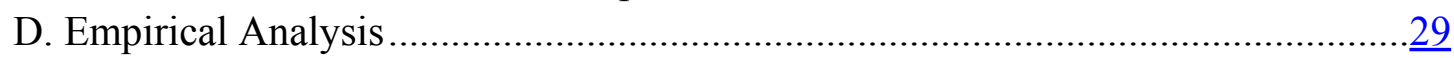

E. Conclusion and Policy Implications ..................................................................

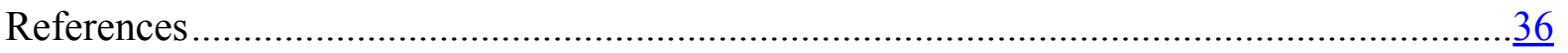


Tables

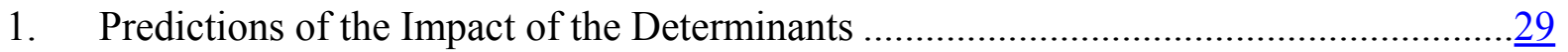

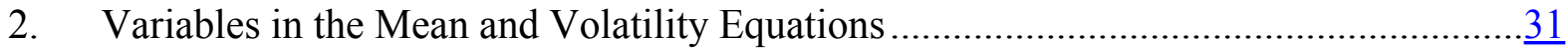

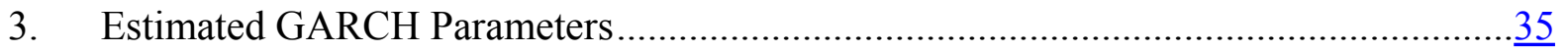

Appendix

1. Structural Liquidity. 


\section{ECONOMIC AND FinANCIAL LinkAgES With THE EURo AREA ${ }^{1}$}

\section{A. Introduction}

1. A subject of much recent academic and policy debate is whether emerging market economies have been able to "decouple" from business cycles in advanced economies, and there has been some empirical evidence supporting the decoupling hypothesis. ${ }^{2}$ However, the financial crisis of 2008-09 told a different, more gloomy story. In particular, in 2009, real GDP level contracted by 6.1 percent in advanced economies, and by 5.4 percent in emerging and developing economies-almost a one-for-one response. The recent re-escalation of financial and sovereign stress in the Euro area has thus renewed concerns about potential spillovers to emerging Europe, including Poland.

\section{This paper takes stock of the economic and financial ties between Poland and the} Euro area and analyzes the associated spillovers. We are particularly interested in measuring the potential impacts of a Euro area shock (real or financial) on Poland's economy. We also investigate the possible channels through which shocks are transmitted across borders.

\section{Business cycles in Poland and the Euro area have become increasingly}

synchronized, as shown by several simple measures based on moments of output growth. For example, the correlation of year-over-year real GDP growth rates between Poland and the Euro area is 0.52 for the entire 1995-2011 sample and 0.81 for post-2004. De-trending the output series using either the univariate (band-pass) or multivariate filters ${ }^{3}$ does not change the main message. Moreover, the Euro area's cycle tends to lead that in Poland by one to two quarters in the post-2004 period, suggesting an important role of external factors in driving Poland's

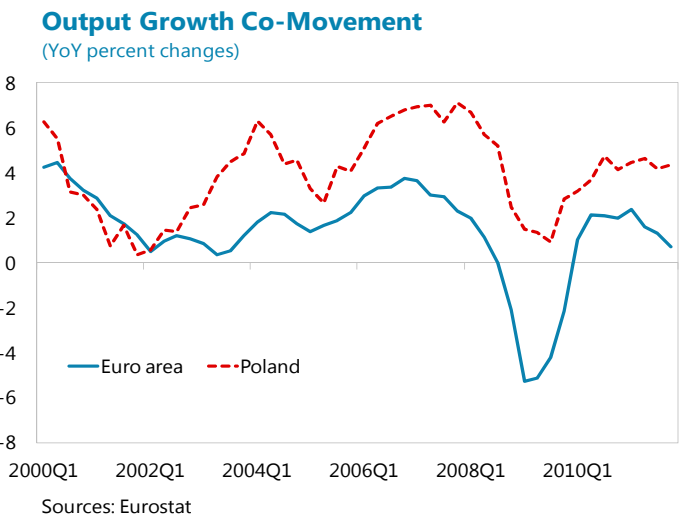
business cycle fluctuations.

Poland: Business Cycle Synchronization with Euro Area

\begin{tabular}{lcc}
\hline Cross correlation & $1995-2011$ & Post-2004 \\
\hline Real GDP growth & 0.52 & 0.81 \\
Band-pass filtered output gap & 0.61 & 0.69 \\
Multivariate filtered output gap & 0.18 & 0.72 \\
\hline
\end{tabular}

\footnotetext{
${ }^{1}$ Prepared by Giang Ho (EUR). Roberto Garcia-Saltos and Michal Andrle (both RES) provide inputs on the Global Projection Model.

${ }^{2}$ See Helbling and others (2007), Kose, Otrok and Prasad (2008).

${ }^{3}$ The multivariate filter uses data on inflation, unemployment, and capacity utilization to measure potential output. See Benes and others (2010) for more detail.
} 


\section{The observed increase in business cycle synchronization can be explained by the} changing nature of shocks or shock transmission, or both. In particular, it is possible that "global" shocks (i.e. shocks common to both countries) have become more volatile, or that country-specific shocks have become more highly correlated. It is also possible that since countries have become more integrated in the goods, capital, and financial markets, country-specific shocks are now more easily transmitted across borders. ${ }^{4}$ Properly disentangling these effects is a difficult task, and beyond the scope of this analysis. We merely conjecture that the greater trade and financial integration between Poland and countries in the Euro area plays a role in further synchronizing the business cycles. ${ }^{5}$

5. The paper is organized as follows. Section B documents stylized facts about trade, vertical integration, foreign direct investment, and banking system linkages between Poland and the core Euro area countries. The subsequent sections attempt to quantify the impact of shocks originating from the Euro area on economic developments in Poland using two methods, namely a vector auto-regression model (Section C) and a small-open-economy quarterly projection model (Section D). Section E contains a few concluding remarks.

\section{B. Trade and Financial Linkages}

\section{Although Poland's economy is less dependent on trade compared to its CEE} neighbors $^{6}$, trade linkages with the Euro area are significant. The value of bilateral trade (exports plus imports) with the Euro area reached over 40 percent of GDP in late 2011, more than double that from fifteen years earlier. Close to 60 percent of Poland's exports go to Euro area countries, half of which are to Germany alone. Other major trading partners include France, Italy, and the UK, although trade with the Netherlands is growing rapidly due to the strong presence of Dutch firms with direct investment in Poland. Recently, an increasingly larger fraction of Polish exports are shifting eastwards to CEE and CIS countries, with especially strong growth in exports to Russia. The geographical structure of

Bilateral Trade Shares (Percent of GDP)

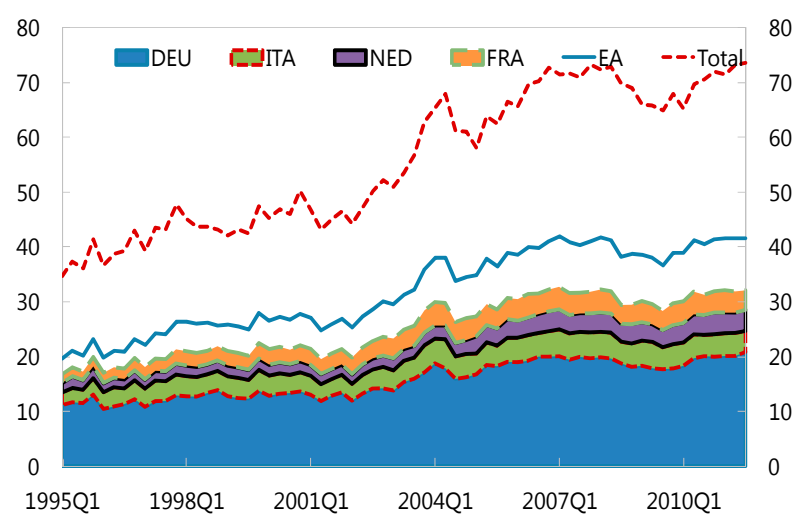

Sources: Direction of Trade Statistics; and IMF staff estimates. imports is broadly similar to that of exports.

\footnotetext{
${ }^{4}$ See Frankel and Rose (1998), Baxter and Crucini (1995) for some early evidence on the role of trade and financial factors in driving international business cycle co-movements.

${ }^{5}$ From a theoretical perspective, however, the correlation between business cycle synchronization and integration is not necessarily positive. Krugman (1993) noted that stronger trade integration may lead to greater regional specialization, which can lead to less output synchronization with industry-specific shocks.

${ }^{6}$ Poland has an exports-to-GDP ratio of 40 percent, compared to an average of 65 percent for new EU member states.
} 
Poland: Trade by Partner, 2010

\begin{tabular}{|c|c|c|c|c|c|c|c|}
\hline \multirow[b]{2}{*}{ Partner } & Balance & \multicolumn{3}{|c|}{ Exports } & \multicolumn{3}{|c|}{ Imports } \\
\hline & $\begin{array}{c}\text { Value } \\
\text { (mil \$US) }\end{array}$ & $\begin{array}{c}\text { Value } \\
\text { (mil \$US) }\end{array}$ & $\begin{array}{c}\text { Share } \\
(\%)\end{array}$ & $\begin{array}{l}\text { Growth } \\
\text { (y/y \%) }\end{array}$ & $\begin{array}{c}\text { Value } \\
\text { (mil \$US) }\end{array}$ & $\begin{array}{c}\text { Share } \\
(\%)\end{array}$ & $\begin{array}{l}\text { Growth } \\
\text { (y/y \%) }\end{array}$ \\
\hline World & $-15,902$ & 154,770 & 100.0 & 13.1 & 170,672 & 100.0 & 13.9 \\
\hline EU countries & 371 & 126,384 & 81.7 & 16.1 & 126,013 & 73.8 & 16.0 \\
\hline Euro area & $-11,813$ & 89,098 & 57.6 & 15.1 & 100,911 & 59.1 & 15.3 \\
\hline Germany & $-8,307$ & 41,706 & 26.9 & 16.8 & 50,013 & 29.3 & 19.0 \\
\hline France & 3,027 & 10,811 & 7.0 & 13.9 & 7,783 & 4.6 & 12.2 \\
\hline Italy & -400 & 9,498 & 6.1 & 1.6 & 9,897 & 5.8 & 0.2 \\
\hline Netherlands & $-3,395$ & 7,009 & 4.5 & 22.0 & 10,404 & 6.1 & 22.5 \\
\hline United Kingdom & 4,739 & 10,045 & 6.5 & 14.3 & 5,306 & 3.1 & 12.8 \\
\hline CEE countries & 6,080 & 13,976 & 9.0 & 19.6 & 7,896 & 4.6 & 18.6 \\
\hline CIS countries & $-5,167$ & 12,583 & 8.1 & 19.2 & 17,750 & 10.4 & 16.5 \\
\hline Russia & $-8,407$ & 6,218 & 4.0 & 23.7 & 14,625 & 8.6 & 15.2 \\
\hline Emerg \& Developing & $-7,118$ & 32,158 & 20.8 & 13.6 & 39,276 & 23.0 & 13.2 \\
\hline United States & -234 & 2,070 & 1.3 & -17.1 & 2,303 & 1.3 & 9.0 \\
\hline
\end{tabular}

\section{The extensive vertical integration between Germany and CEE countries is}

boosting trade in Poland. 7 Vertical integration between Germany and CEE countries primarily involves production of transport equipment, particularly automobiles, with Germany generally taking a more upstream position and supplying more intermediate inputs. One measure of vertical integration is the size of trade in intermediate and capital goods, which shows the extent to which production processes are geographically fragmented. Trade in intermediate and capital goods accounted for roughly half of total trade between Poland and Germany in $2010^{8}$; however, this share has remained roughly constant over the 2000-10 period. An alternative measure of vertical integration is the import content of exports. For example, the share of foreign value added in Poland's gross exports of durable goods increased from 19 percent in 1995 to almost 43 percent in 2005. ${ }^{9}$ Close to 30 percent of this foreign value added in 2005 originated from Germany. Automobiles account for 13 percent of Poland's trade with Germany, of which 80 percent is parts and components, and the remaining 20 percent is final vehicles.

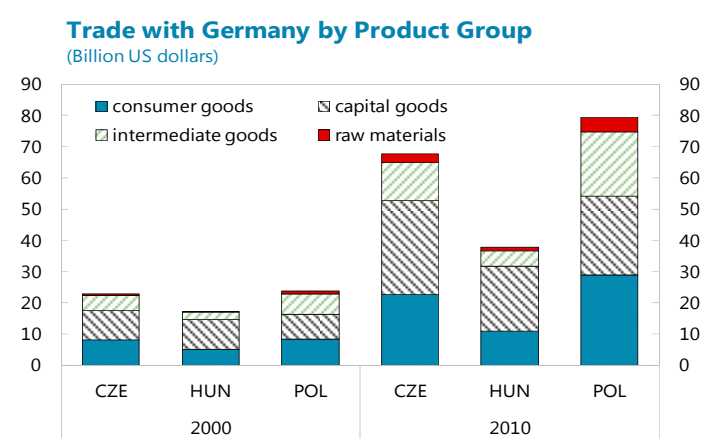

Sources: UN Comtrade database; and IMF staff estimates.

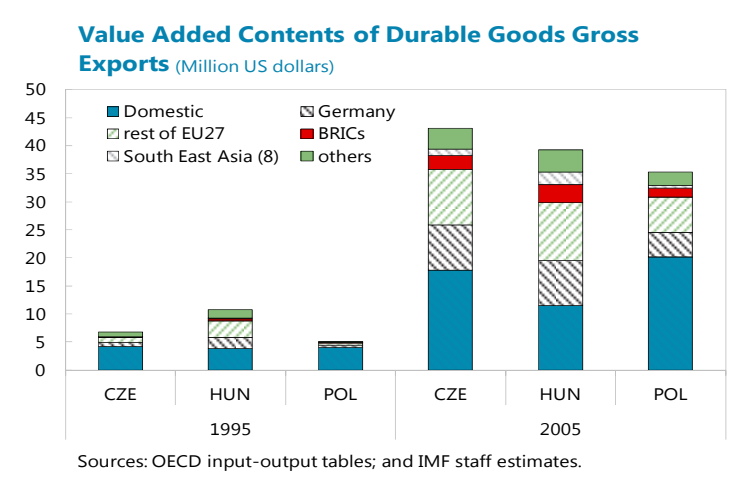

\footnotetext{
${ }^{7}$ See Hummels, Ishii and Yi (2001) for evidence on the growth of vertical integration in world trade.

${ }^{8}$ The classification of intermediate and capital goods follows HS standard product grouping in UN Comtrade database.

${ }^{9}$ See the study by Strategy, Policy and Review Department (2011), which calculate the import content of exports for a number of countries using OECD input-output databases.
} 


\section{Vertical integration may be an important channel transmitting business cycle}

shocks across borders. For example, using cross-country industry-level data, di Giovanni and Levchenko (2009) find that vertical specialization accounts for roughly 30 percent of the total impact of bilateral trade on business cycle correlation. Bems and others (2010) use a global input-output framework and calculate that during the Great Recession, for every percentage point drop in Western Europe's output growth caused by declining final demand, growth in emerging Europe dropped by 0.35 percentage points.

9. Substantial foreign direct investment (FDI) further fosters trade links. For Poland, the share of FDI in GDP reached over 40 percent in 2010, twice that in 2000. Three quarters of this FDI are accounted for by investors from the Euro area. Dutch, German, and French firms dominate inward investment activity, whereas Polish firms maintain sizable direct investment position in Italy and Luxembourg, most likely in financial services. Across the CEE, the industry composition of inward FDI varies substantially. While a relatively large fraction of FDI in Poland and the Czech Republic go to the manufacturing sector, which is arguably harder to reverse, most FDI in Hungary is channeled into financial intermediation and real estate. Consequently, while Poland and the Czech Republic both experienced a significant reduction of FDI inflows during the 2008-09 crisis, unlike Hungary there was no outflow.

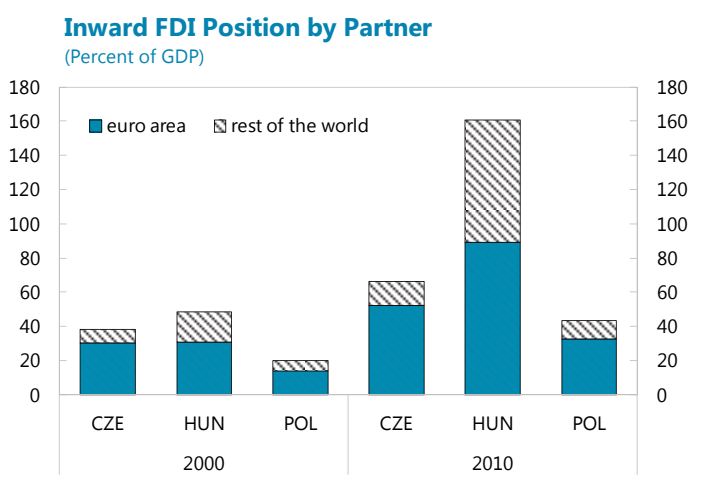

Sources: OECD Stat; and IMF staff estimates.

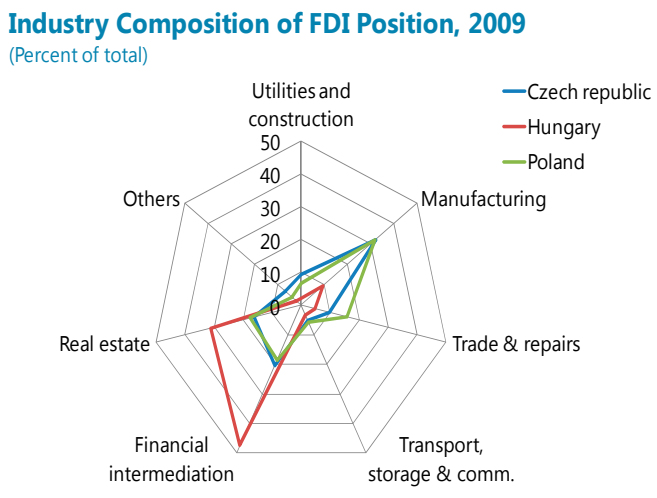

Sources: OECD Stat; and IMF staff estimates.

Poland: Foreign Direct Investment Position by Partner, 2010

\begin{tabular}{c|rr|rr}
\hline \multirow{2}{*}{ Partner } & \multicolumn{2}{|c|}{ Inward FDI } & \multicolumn{2}{c}{ Outward FDI } \\
\cline { 2 - 5 } & \multicolumn{2}{c}{ Value } & $\begin{array}{c}\text { Share } \\
\text { (mil \$US) }\end{array}$ & \multicolumn{2}{c}{$\begin{array}{c}\text { Value } \\
\text { (mil \$US) }\end{array}$} & \multicolumn{1}{c}{$\begin{array}{c}\text { Share } \\
(\%)\end{array}$} \\
\hline World & 202,570 & 100.0 & 39,334 & 100.0 \\
EU countries & 174,394 & 86.1 & 28,856 & 73.4 \\
Euro area & 153,976 & 76.0 & 19,907 & 50.6 \\
Netherlands & 36,109 & 17.8 & 2,925 & 7.4 \\
Germany & 27,461 & 13.6 & 2,442 & 6.2 \\
France & 25,165 & 12.4 & 262 & 0.7 \\
Luxembourg & 17,682 & 8.7 & 9,193 & 23.4 \\
Italy & 14,177 & 7.0 & 14,177 & 36.0 \\
CEE countries & 1,354 & 0.7 & 5,882 & 15.0 \\
CIS countries & 566 & 0.3 & 2,627 & 6.7 \\
United States & 12,483 & 6.2 & 1,108 & 2.8 \\
\hline
\end{tabular}


10. The banking systems of Poland and the Euro area have also become increasingly integrated. Exposure to BIS-reporting banks, counting both cross-border lending and locallyfunded assets of foreign bank subsidiaries, reached almost 60 percent of GDP in late 2011. More than 80 percent of foreign claims are accounted for by Euro area banks, with German, Italian, and Dutch banks in the lead. Exposure to banks in IMF-program countries (Greece, Ireland, and Portugal) is limited, amounting to less than five percent of GDP in 2011. The majority of foreign bank loans (direct and subsidiary lending) are extended to the private non-bank sector. Bank loans represent an important source of finance for Polish enterprises, accounting for about a quarter of total enterprise sector liabilities..$^{10}$

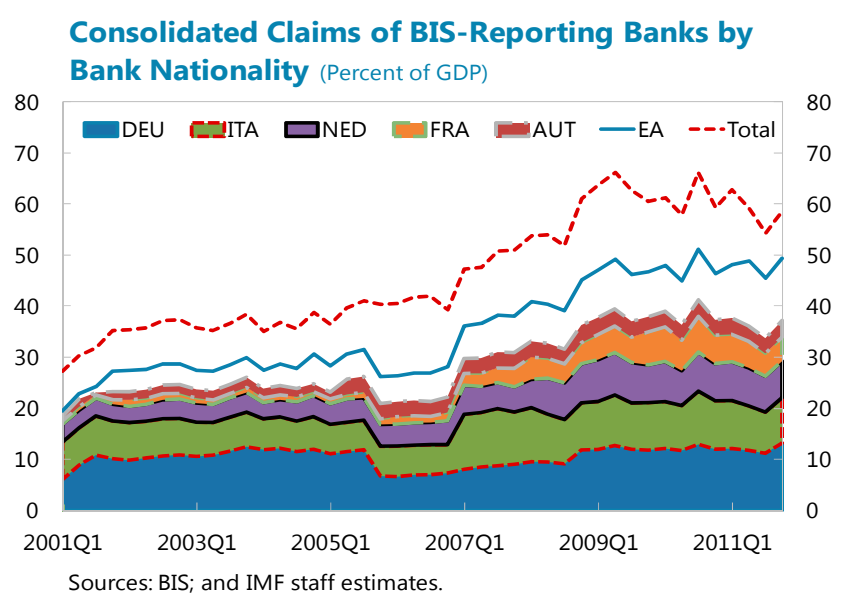

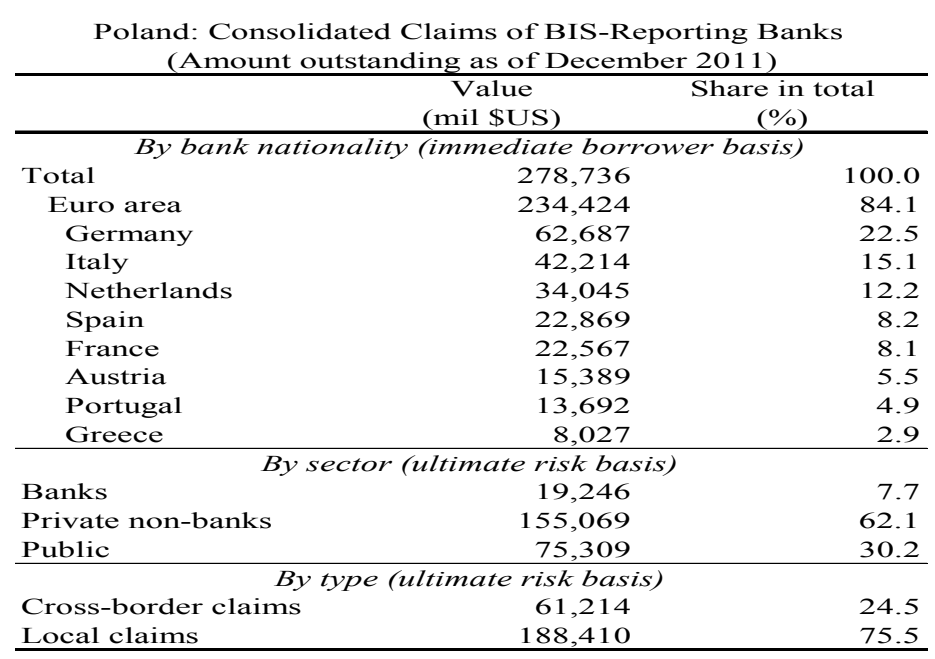

\section{In summary, Poland is increasingly integrated with the core Euro area countries} through both trade and financial channels. Poland holds a key position in the German supply chain, and is a recipient of substantial and diverse FDI from the core Euro area countries. Both factors contribute to the significant size of bilateral trade, making Poland vulnerable to a negative growth shock in the Euro area through the external demand channel. Further, the sizable foreign ownership of Poland's banking system also increases the risks that a financial shock in the Euro area will be transmitted to Poland's financial sector and consequently to the real economy.

\footnotetext{
${ }^{10}$ National Bank of Poland's “Financial Stability Report,” December 2011.
} 
12. The following sections offer two approaches to analyze spillovers from the Euro area to Poland. The first attempts to quantify the size of growth spillovers and the relative contribution of various transmission channels (trade, financial, commodity prices) using a simple vector auto-regression (VAR) framework. ${ }^{11}$ The second approach simulates the effects of a financial shock in the Euro area on the domestic economy using the Global Projection Model (GPM).

\section{Vector Auto-Regression}

\section{We estimate a VAR model that contains quarterly real GDP growth for Poland, the Euro area, and the rest of the world (ROW) for the period 1997:Q2-2011:Q3. ${ }^{12}$ To} identify the impulse responses to a country-specific shock, Cholesky decomposition is used to orthogonalize the errors across individual VAR equations. It is well-known that the results obtained this way are sensitive to the ordering of variables in the decomposition, which assumes the region/country from which disturbances originate. As an attempt to mitigate this problem, we follow Bayoumi and Swiston (2007) and take the average of "plausible" Cholesky orderings - a quasi-Bayesian approach that essentially assigns priors to the direction of causality. Specifically, we assume that shocks originate from the Euro area with probability one-half and from the rest of the world with probability one-half. Since Poland is a small economy compared to the other two regions, any contemporaneous correlation between Poland's residuals and those of the major regions is assumed to be driven by the larger economies. $^{13}$

\section{Examination of the VAR residuals shows that external shocks have become} relatively more important than domestic shocks in driving the volatility of Poland's economy. Domestic shocks have become less volatile, as indicated by a decline in the estimated standard deviation from 2.5 for the entire sample to 1.84 for the post-2004 sample. Meanwhile, the correlation with Euro area's shocks has increased ( 0.35 in full sample vs. 0.49 in post-2004 sample). Lower domestic shock volatility and higher correlation with external shocks offset each other, keeping the covariance between Poland's shocks and Euro area's shocks relatively stable over time.

\footnotetext{
${ }^{11}$ This approach is similar to that developed by Bayoumi and Swiston (2007-08).

${ }^{12}$ The ROW aggregate consists of the United States and 12 smaller countries: Australia, Canada, Denmark, New Zealand, Norway, Sweden, Switzerland, United Kingdom, Korea, Mexico, South Africa, and Taiwan. The aggregate growth rate is calculated by weighting each country's growth rate by its PPP GDP.

${ }^{13}$ Although we are not able to satisfactorily control for common or global shocks in this simple framework, we expect the ROW aggregate to pick up some of the effects of global shocks, being an aggregate of countries that are diverse in geography and industrial structure.
} 


\begin{tabular}{lcc}
\multicolumn{3}{c}{ Variances, Correlations, and Covariances of VAR Residuals } \\
\hline & $\begin{array}{c}\text { Full sample } \\
(97: \text { Q2-11:Q3) }\end{array}$ & $\begin{array}{c}\text { Post-2004 sample } \\
(04: Q 1-11: Q 3)\end{array}$ \\
\hline Standard deviation & 2.50 & 1.84 \\
POL & 1.41 & 1.39 \\
EUR & 1.30 & 1.36 \\
ROW & & \\
Correlation & & 0.49 \\
(POL, EUR) & 0.35 & 0.49 \\
(POL, ROW) & 0.22 & 0.77 \\
(EUR, ROW) & 0.64 & \\
Covariance & & 1.25 \\
(POL, EUR) & 1.23 & 1.22 \\
(POL, ROW) & 0.71 & 1.45 \\
(EUR, ROW) & 1.17 &
\end{tabular}

\section{Impulse response results show that spillovers from a growth shock in the Euro} area to Poland's economy can be sizable. A typical shock to Euro area's growth is estimated at 1.25 percentage points on impact, rising to around 4 percentage points after two years. In response, Poland's growth increases by 0.78 percentage points initially, accumulating to a peak of just over one percentage point after four quarters. Thus, the cumulative response of Poland's growth to a Euro area shock is 60 percent of the original shock on impact, averaging 30 percent over two years.

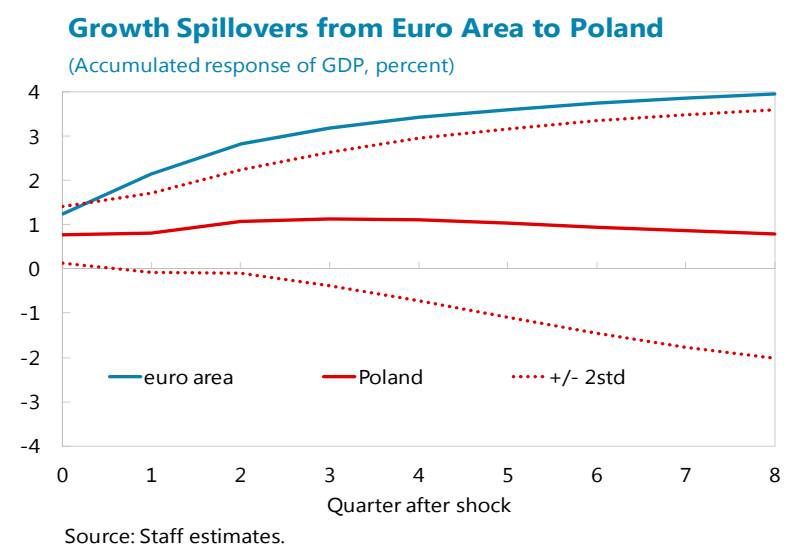

\section{We estimate the contribution of three potential transmission channels, namely} trade, financial, and commodity prices, to the overall growth spillovers. The three-variable VAR above is augmented by adding each of the channels as exogenous variables in separate estimations. ${ }^{14}$ The impulse response given by a VAR augmented with trade variables, for example, can be thought of as measuring the spillovers through all channels other than trade. Thus, we can calculate the contribution of a particular channel as the difference in response between the augmented VAR and the original VAR:

$$
c_{i, j}=r_{i}-r_{i, j}
$$

where $c_{i, j}$ denotes the contribution of channel $j$ in period $i, r_{i}$ is the response from the original $\mathrm{VAR}$, and $r_{i, j}$ is the response from the VAR augmented with channel $j$.

\footnotetext{
${ }^{14}$ Thus, the implicit assumption is that the three transmission channels are uncorrelated. Following Bayoumi and Swiston (2007), we use net export contribution to real GDP growth to measure the trade channel, and equity prices, short and long-term interest rates of the two major regions to measure the financial channel. To capture the commodity price channel, we include in the regression the S\&P Goldman Sachs Commodity Index.
} 


\section{Contributions from the trade and financial channels are estimated to be the most} significant, while commodity prices play a limited role. Financial conditions in the Euro area explain a major part of the overall growth spillovers to Poland, especially during the first two quarters immediately after shock. While trade variables are relatively less important for the cross-country transmission of shocks during the first few quarters, contribution of the trade channel increases over time. The sum of contributions from the individual channels is not constrained to equal the estimated overall response from the original VAR, and thus could be used as an alternative estimate of the size of growth spillovers..$^{15}$

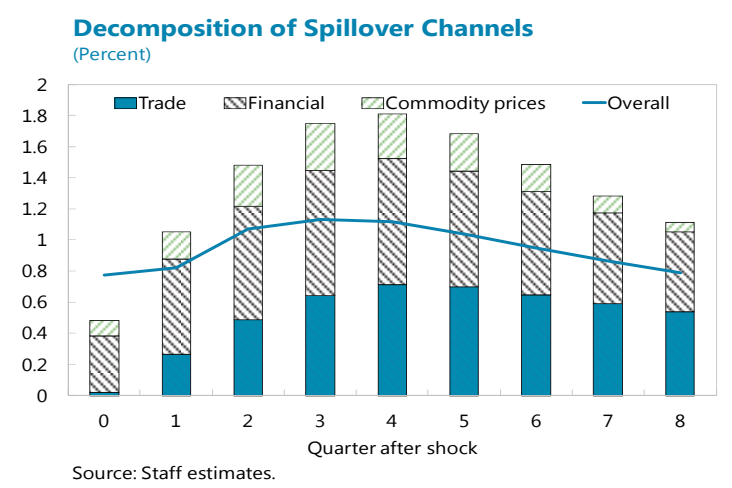

18. In summary, the simple VAR exercise produces two main findings. First, growth spillovers from the Euro area to Poland are non-trivial, with an estimated growth elasticity of 0.6 on impact and 0.3 on average over two years. In terms of magnitude, this is however significantly lower than the estimate for entire Central Europe (almost one-for-one) ${ }^{16}$, possibly due to the relative closedness of Poland's economy. Second, shocks are transmitted from the Euro area to Poland primarily through trade and financial channels, with financial factors playing the dominant role in the period immediately after shock.

\section{Global Projection Model}

\section{We develop a small quarterly projection model of Poland and the Euro area,} which features real-financial linkages as well as financial integration between the two economies. This is a parsimonious variant of the Fund's Global Projection Model developed in a series of papers ${ }^{17}$ and is designed to focus primarily on the potential contagion from the Euro area to Poland given the extensive trade and financial linkages documented above. The model is characterized by a few core forward-looking behavioral equations that jointly determine key macroeconomic variables, namely output, unemployment, inflation, short-term interest rate,

\footnotetext{
${ }^{15}$ The fact that the individual channels add up to more than the estimated overall response could indicate that the channels as measured here are not independent. For example, if difficult financial conditions in the Euro area translate into a dry-up of trade financing for Polish exporters which in turn affect Poland's exports, this effect will be captured in the estimates of both the financial and trade channels.

${ }^{16}$ See Akinci and Jeasakul (2011), Chapter 4 of the Regional Economic Outlook: Europe. Central Europe comprises the Czech Republic, Hungary, Poland, the Slovak Republic, and Slovenia. The estimated growth elasticity is with respect to Western Europe, which includes the Euro area together with Denmark, Iceland, Norway, Sweden, Switzerland, and the United Kingdom.

${ }^{17}$ See Andrle and others (2009) and Epstein (2011).
} 
and the exchange rate. Model parameters are chosen based on a combination of theory, historical data, expert judgment, and estimated parameters from the GPM $6{ }^{18}$.

\section{A central feature of our model is the incorporation of an external finance}

premium (XFP). This premium is defined as the spread between the risk-free rate and the lending rate for nonfinancial firms and households, reflecting the cost of financial intermediation faced by profit-maximizing banks. ${ }^{19}$ This spread is observed to be countercyclical, reflecting developments in credit supply conditions, and seeks to capture a channel of real-financial linkage and cross-country contagion that goes beyond the traditional channels of interest rate and exchange rate.
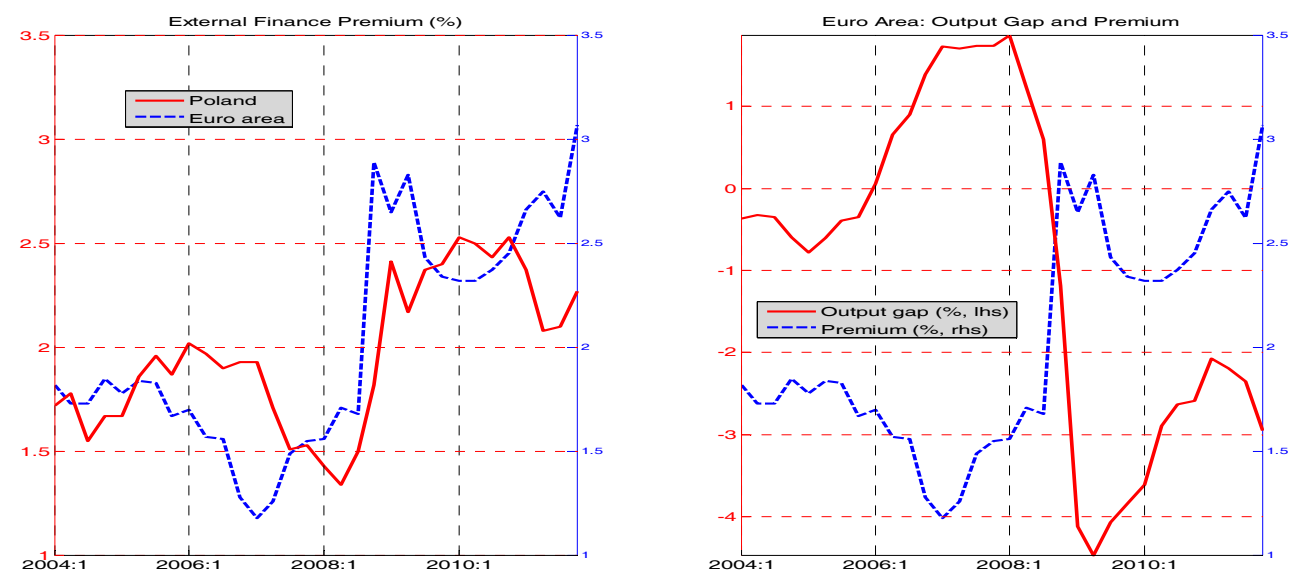

\section{The external finance premium played an important role in the Great Recession,} when much of the shock was financial in nature. While the majority of modern recessions prior to 2008-09 were the result of monetary policy tightening to bring down inflation, which was then transmitted to the real economy via the interest rate channel, the onset of the 2008-09 crisis was marked by a sharp and extremely persistent increase in XFP. In particular, the premium in the Euro area increased by 120bps between 2008:Q3 and Q4, and in Poland it increased by roughly 60bps between 2008:Q4 and 2009:Q1. The higher premium initially reflected a drying up of liquidity in the interbank market and the squeeze in credit supply as a result of bank deleveraging, and subsequently elevated default risks of households and firms as the economic outlook weakened. The figure shows that XFP in the Euro area and Poland are highly correlated, in part due to the significant presence of Euro area's banks in the Polish

\footnotetext{
${ }^{18}$ The GPM6 is a small quarterly model covering six regions: United States, the Euro area, Japan, emerging Asia, the five Latin America inflation-targeting countries, and a remaining countries grouping. The model is estimated using Bayesian methods. See Carabenciov and others (2012) for more detail.

${ }^{19}$ In the Costly State Verification (CSV) type of models, as in e.g. Bernanke, Gertler and Gilchrist (1999), Christiano, Motto and Rostagno (2010), this is the cost of overcoming the information asymmetry between the lenders and the borrowers. To compute the empirical spreads, we use the reference rates for Poland and the Euro area as a measure of the risk-free rate. As the lending rate, we use the loan rate for nonfinancial firms (excluding overdraft) for Poland, and the rate on new business loans of 1-to-5-year maturity for the Euro area.
} 
banking system ${ }^{20}$, and that a rise in premium is a potential indicator of subsequent economic downturn. The cross-correlation structure of the two premium series serves as a basis for our choice of the magnitude of cross-country financial spillovers in the model.

\section{We study the impulse responses of key variables to a scenario of intensified}

financial stress in the Euro area (Figure 1). In particular, we assume that, under an adverse financial shock, the Euro area's external finance premium increases by $100 \mathrm{bps}$ for one quarter. Due to the spillovers, Poland's premium quickly increases in response, peaking at $25 \mathrm{bps}$ three quarters after the original shock. As a result, the output gap drops by 0.3 percentage point in the Euro area and 0.2 percentage point in Poland. The impact of the financial shock on the domestic economy is persistent: the accumulated output loss relative to baseline (no shock) amounts to 1.5 percentage points over three years. While the negative effect on output in the Euro area results exclusively from the higher financing cost, Poland's output is affected both directly via premium shock spillovers and indirectly via weak foreign demand. Depressed domestic demand reduces inflationary pressures despite some offsetting pass-through effect from a depreciation of the exchange rate. Assuming monetary policy is operating under no constraints, central banks in both economies respond by cutting the short-term interest rate to boost the economy. The model predicts that the NBP would have reduced the policy rate by a cumulative 280 basis points by the end of year three.

\section{We now examine a scenario in which the two economies are faced with the same} premium shock but monetary policy reaction is delayed (Figure 2). In particular, in the first scenario (blue dash lines), the European Central Bank is constrained by the binding zero-lower-bound and thus cannot lower the nominal interest rate for four quarters. In the second scenario (red dash-dot lines), Poland's central bank delays its reaction by one quarter, for example due to concerns over the impact of rising global risk aversion on the exchange rate (and therefore inflation, given pass-through). In each case, agents in the model are assumed to fully anticipate the central bank's inaction and act accordingly. The simulation shows that under NBP inaction even for just one quarter, the domestic economy suffers from a significantly deeper downturn compared to the scenario with instant policy reaction (black lines). The effects are much less severe when the policy constraint is on the part of the ECB. This is because, although Poland would be affected through the external demand channel, the immediate reduction in the domestic interest rate brings about a large exchange rate depreciation, mitigating the negative output response by supporting net exports. ${ }^{21}$ The experiment highlights the cushioning role of monetary policy in Poland in counteracting adverse external shocks.

\footnotetext{
${ }^{20}$ Enders and others (2011) provide a micro-founded theory for the international transmission of financial shocks by incorporating a "global bank" into a two-country business cycle model.

${ }^{21}$ Given the significant dollarization in Poland's credit market, exchange rate depreciation may also lead to negative balance sheet effects that counteract the positive external demand channel.
} 


\section{Box 1. Key Model Equations}

The domestic economy is characterized by five core behavioral equations that jointly determine the output gap, inflation, short-term nominal interest rate, exchange rate, and unemployment gap ${ }^{22}$.

- $\quad$ IS curve (aggregate demand)

$$
y_{t}=\beta_{1} y_{t-1}+\beta_{2} y_{t+1}-\beta_{3} r_{t}-\beta_{4}\left(\mu_{t}-\mu_{s s}\right)+\beta_{5} z_{t}+\beta_{6} y_{t}^{E U}+\varepsilon_{t}^{y}
$$

This equation relates the output gap $\left(y_{t}\right)$ to its own lead and lagged values, the real interest rate gap $\left(r_{t}\right)$, the deviation of the external finance premium from its steady-state value $\left(\mu_{t}-\mu_{s s}\right)$, the real exchange rate gap $\left(z_{t}\right)$, and the output gap in the Euro area $\left(y_{t}^{E U}\right)$ which captures the direct trade link between the two economies. XFP follows an autoregressive process with direct spillovers from the premium in the Euro area, and the strength of spillovers is governed by the parameter $c_{-}$spill :

$$
\mu_{t}=\rho_{\mu} \mu_{t-1}+\left(\overline{1-} \rho_{\mu}\right)\left[\mu_{s s}+c_{-} \operatorname{spill}\left(\mu_{t}^{E U}-\mu_{s s}^{E U}\right)\right]+\varepsilon_{t}^{\mu}
$$

- $\quad$ Phillips curve (inflation)

$$
\begin{gathered}
\pi_{t}=\pi_{t}^{c}+\varepsilon_{t}^{\pi} \\
\pi_{t}^{c}=\lambda_{1} \pi_{t+1}^{c}+\left(1-\lambda_{1}\right) \pi_{t-1}^{c}+\lambda_{2} y_{t}+\lambda_{3} z_{t}+\varepsilon_{t}^{\pi^{c}}
\end{gathered}
$$

Headline inflation $\left(\pi_{t}\right)$ is modeled as the sum of a measure of core inflation $\left(\pi_{t}^{c}\right)$ and an i.i.d shock capturing highfrequency dynamics $\left(\varepsilon_{t}^{\pi}\right)$. Core inflation is a function of both its past and future values, the output gap, the real exchange rate gap, and a mark-up shock $\left(\varepsilon_{t}^{\pi^{c}}\right)$.

- Monetary policy rule

$$
i_{t}=\gamma_{1} i_{t-1}+\left(1-\gamma_{1}\right)\left[\overline{r_{t}}+\pi_{t+1}^{t a r}+\gamma_{2}\left(\pi 4_{t+4}-\pi_{t+4}^{t a r}\right)+\gamma_{3} y_{t}\right]+\varepsilon_{t}^{i}
$$

The short-term nominal interest rate $\left(i_{t}\right)$ is determined by a variant of the Taylor's rule. The central bank aims at achieving a measure of the equilibrium nominal interest rate over the long run $\left(\overline{r_{t}}+\pi_{t+1}^{t a r}\right)$, while responding to deviations of the expected year-on-year inflation from the inflation target $\left(\pi 4_{t+4}-\pi_{t+4}^{t a r}\right)$ and to the current output gap, as well as smoothing interest rate movements (lagged term).

- Uncovered interest parity (UIP)

$$
i_{t}-i_{t}^{E U}=4\left(E s_{t+1}-s_{t}\right)+\bar{\rho}_{t}+\varepsilon_{t}^{u i p}
$$

The UIP equation relates the interest rate differential between the two countries to the expected change in the nominal exchange rate $\left(E s_{t+1}-s_{t}\right)$ and an equilibrium risk premium on zloty-denominated assets

$\left(\bar{\rho}_{t}\right)$. The expected nominal exchange rate $\left(E s_{t+1}\right)$ is defined as a weighted average of model-consistent solution of the exchange rate 1 period ahead ( $s_{t+1}$ ) and a backward-looking estimate of $E s_{t+1}$, where $\Delta \bar{s}_{t}$ denotes the annualized quarter-on-quarter change in the equilibrium exchange rate.

$$
E s_{t+1}=\phi s_{t+1}+(1-\phi)\left(s_{t-1}+2 \Delta \bar{s}_{t} / 4\right)
$$

- Dynamic Okun's law

$$
u_{t}=\alpha_{1} u_{t-1}+\alpha_{2} y_{t}+\varepsilon_{t}^{u}
$$

The unemployment gap $\left(u_{t}\right)$ is a function of its lagged value and the contemporaneous output gap.

The "foreign block" of the model contains the following main equations for the Euro area:

$$
\begin{gathered}
y_{t}^{E U}=\tilde{\beta}_{1} y_{t-1}^{E U}+\tilde{\beta}_{2} y_{t+1}^{E U}-\tilde{\beta}_{3} r_{t}^{E U}-\tilde{\beta}_{4}\left(\mu_{t}^{E U}-\mu_{s s}^{E U}\right)+\tilde{\varepsilon}_{t}^{y} \\
\mu_{t}^{E U}=\tilde{\rho}_{\mu} \mu_{t-1}^{E U}+\left(1-\tilde{\rho}_{\mu}\right) \mu_{s s}^{E U}+\tilde{\varepsilon}_{t}^{\mu} \\
\pi_{t}^{c, E U}=\tilde{\lambda}_{1} \pi_{t+1}^{c, E U}+\left(1-\pi_{t}^{c, E U}+\tilde{\lambda}_{1}\right) \pi_{t-1}^{c, E U}+\tilde{\lambda}_{2} y_{t}^{E U}+\tilde{\varepsilon}_{t}^{\pi^{c}} \\
i_{t}^{E U}=\tilde{\gamma}_{1} i_{t-1}^{E U}+\left(1-\tilde{\gamma}_{1}\right)\left[\bar{r}_{t}^{E U}+\pi_{t+1}^{t a r, E U}+\tilde{\gamma}_{2}\left(\pi 4_{t+3}^{E U}-\pi_{t+3}^{t a r, E U}\right)+\tilde{\gamma}_{3} y_{t}^{E U}\right]+\tilde{\varepsilon}_{t}^{i}
\end{gathered}
$$

22 "Gap" variables refer to deviation from equilibrium values. Variables denoted with a "bar" refer to equilibrium values. 


\section{Underlying this exercise is a crucial assumption about the persistence of the} premium shock in the Euro area. In particular, if households and firms expect financing costs to remain elevated for a long period of time, the cut back in consumption and investment would likely be more substantial. The shock persistence is primarily governed by the autocorrelation parameter of the premium process for the Euro area $\left(\tilde{\rho}_{\mu}\right)$. In Figure 3, we study the effects of a higher persistence parameter, i.e. $\tilde{\rho}_{\mu}=0.8$ compared to the baseline value of 0.7. As expected, a more persistent increase in Euro area's finance premium is associated with a larger reduction in the domestic output gap and inflation, and in response Poland's central bank reduces the policy rate more aggressively by roughly $20 \mathrm{bps}$ relative to the baseline. Again, both trade and financial channels play a role. The financial consequence would be more severe in a plausible scenario where, faced with a more persistent shock to the Euro area's premium, Polish consumers perceive that the resulting increase in domestic premium would also be more persistent (higher $\rho_{\mu}$ ).

\section{Unlike persistence of the premium shock, the model results are relatively} insensitive to changes in the magnitude of the spillover parameter (Figure 4). In particular, in the baseline we choose the spillover parameter $c_{-}$spill $=0.76$ to reflect the estimated cross-correlation between Poland's and the Euro area's historical premium. In the scenario with stronger spillovers, e.g. due to a more closely integrated banking system than in the past, we let $c$ spill $=0.95$. Compared to the previous scenario of higher shock persistence, the responses of domestic output, inflation, interest rate and exchange rate are relatively insensitive to changes in the spillover parameter.

\section{We proceed to confront the model with observed data and examine how the model} interprets history. Specifically, using historical data on output, inflation, unemployment, exchange rate and the policy rate, the parameterized model can be used to estimate the various structural shocks as well as the unobservable quantities such as the output gap and the equilibrium exchange rate. We then decompose the estimated output gap series for Poland over the period 2004:Q1-2011:Q4 into relative contributions of the structural shocks. ${ }^{23}$ This exercise allows us to evaluate, in the model's eyes, what are the important sources of shocks driving Poland's economy during the past eight years.

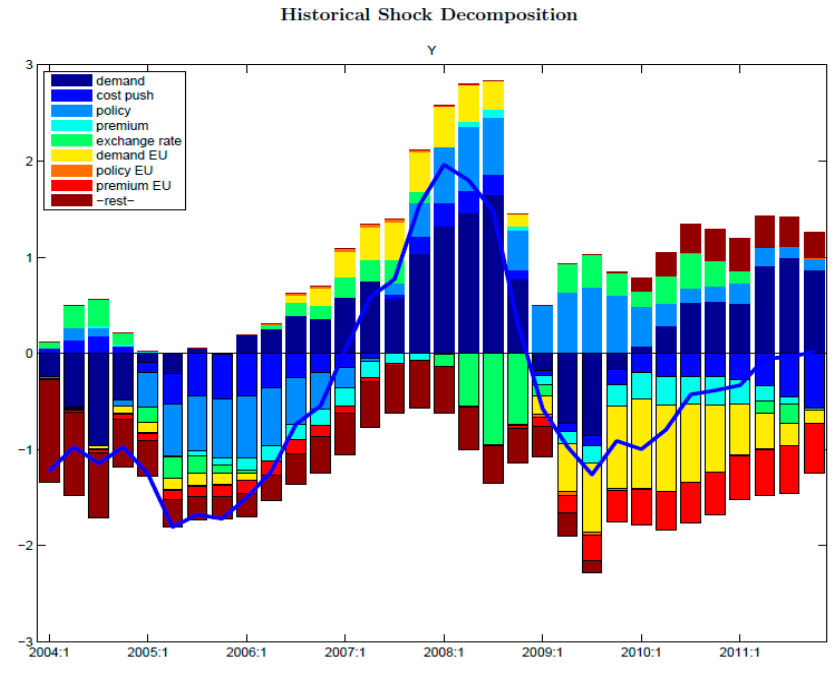

\footnotetext{
${ }^{23}$ The numerous shocks in the model are grouped into a few broad categories for expositional clarity.
} 


\section{The historical shock decomposition shows that shocks from the Euro area play a major role in driving Poland's business cycle fluctuations, particularly in the recent} period. In particular, the contrast between the 2005-06 downturn and the past financial crisis is remarkable. During the 2005-06 period, domestic policy shocks were the main driver of the output gap, and there was very little contribution from either demand or financial factors. On the other hand, the 2008-09 downturn was driven primarily by adverse shocks to domestic and foreign demand as well as by premium shocks in both countries, with Euro area shocks accounting for roughly half of the total negative contributions. While the subsequent recovery was supported by a rebound in domestic demand, external factors including the persistently high Euro area finance premium continued to weigh on the recovery. The decomposition also shows that Poland's monetary policy stance was supportive to growth during and in the aftermath of the crisis; the NBP indeed reduced the policy rate by a cumulative 250bps between 2008:Q3 and 2009:Q3. Finally, while premium shocks tend to be pro-cyclical, exchange rate movements were instrumental in smoothing out Poland's cyclical fluctuations.

\section{E. Concluding Remarks}

\section{Poland is increasingly integrated with the Euro area through trade, vertical integration, FDI, and banking channels, giving rise to strong (positive and negative)} spillovers. Using a simple VAR framework, we estimate that growth spillovers from the Euro area to Poland can be sizable with an elasticity of 0.6 on impact, and that growth shocks are transmitted through primarily trade and financial channels. Incorporating cross-country financial linkages into the Global Projection Model allows us to study the endogenous responses of the output gap, inflation, exchange rate, and particularly monetary policy to an external financial shock. The historical shock decomposition confirms that real and financial shocks from the Euro area have become a major driver of Poland's business cycle fluctuations.

\section{It is analytically challenging to measure spillovers across countries and determine}

the contributing factors. The methods illustrated here, while promising, are subject to several caveats. Among the most criticized issues with non-structural methods like VARs are how to properly identify the effects of country-specific shocks (i.e. stripped of common shocks) and how to condition the responses on a set of initial conditions (e.g. spillovers may be asymmetric between upturns and downturns). The Global Projection Model provides a consistent approach to forecasting, policy analysis and risk assessment, with appropriate consideration of relevant foreign developments and the potential spillover channels. It is also sufficiently simple to allow effective communication of policy results, an advantage that large micro-founded models do not possess. However, the price to be paid for simple intuition is the omission of important aspects such as fiscal policy, and the treatment of financial sector remains at a rudimentary stage. It is hoped that as the sophistication of analytical tools improves, future analysis of cross-country spillovers will also benefit. 
Figure 1. Responses to Euro Area Premium Shock
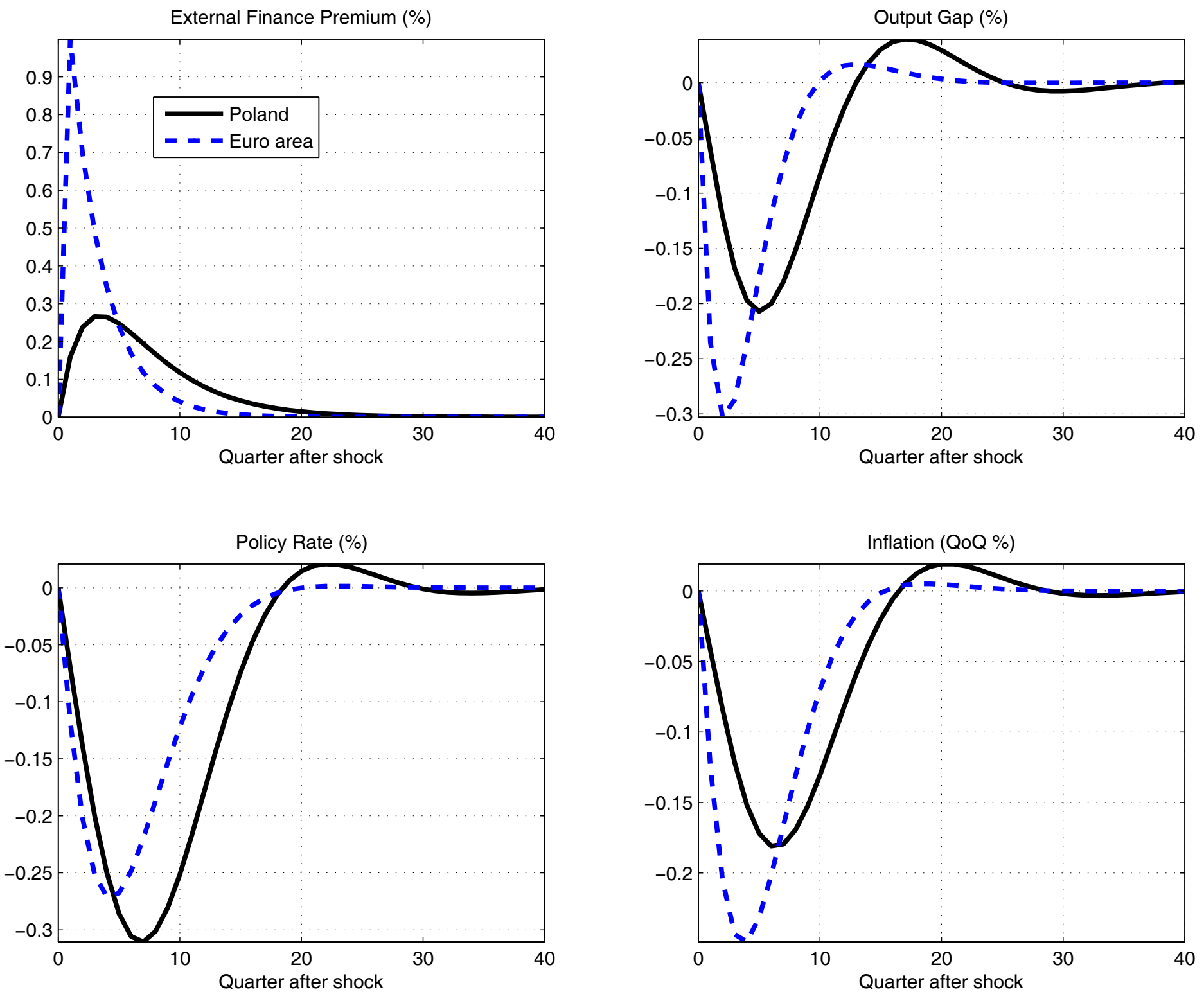

Source: GPM simulation.

CInternational Monetary Fund. Not for Redistribution 
Figure 2. Responses to Euro Area Premium Shock with Anticipated Monetary Policy Delay
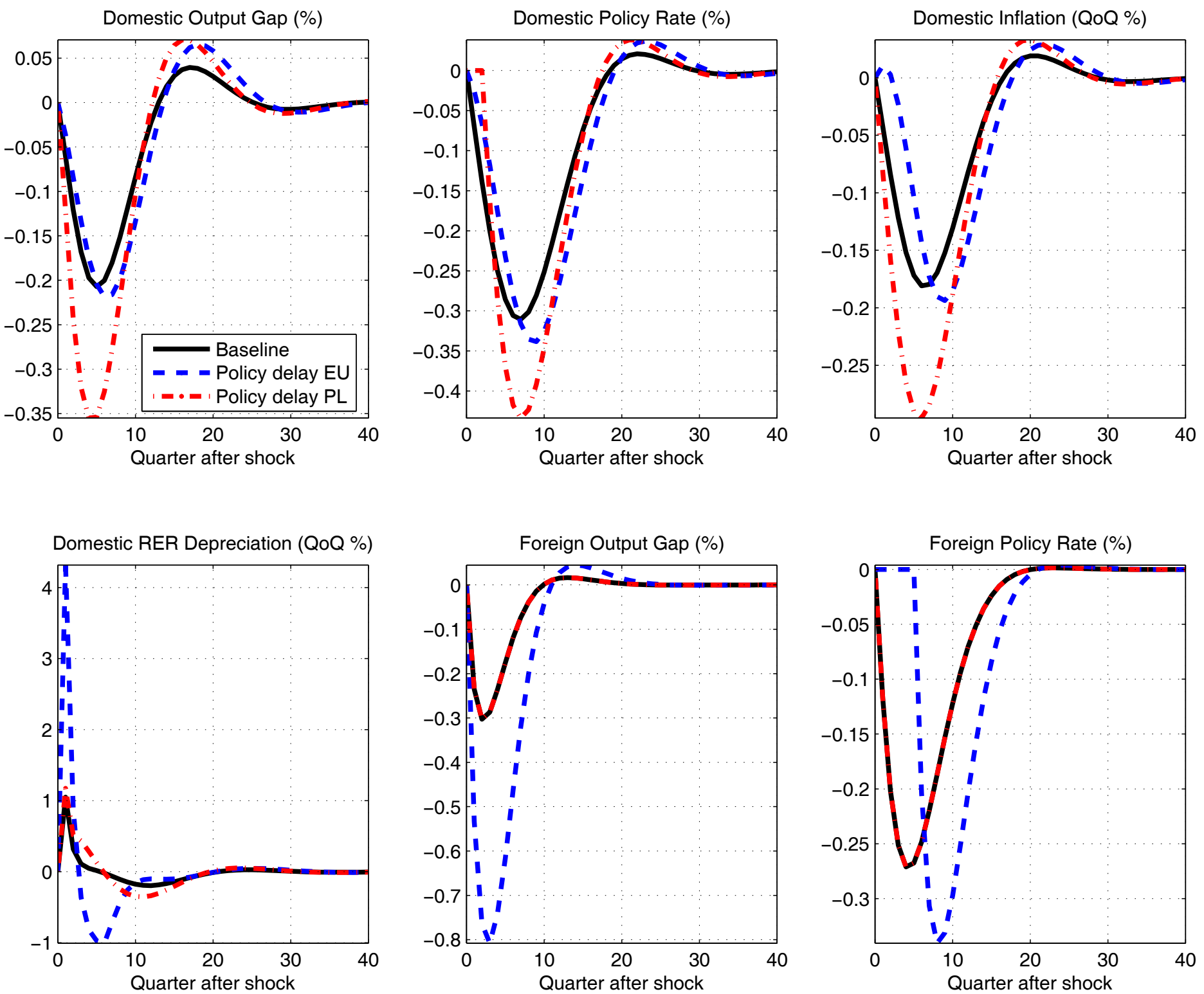

Source: GPM simulation.

CInternational Monetary Fund. Not for Redistribution 
Figure 3. Responses to a More Persistent Euro Area Premium Shock
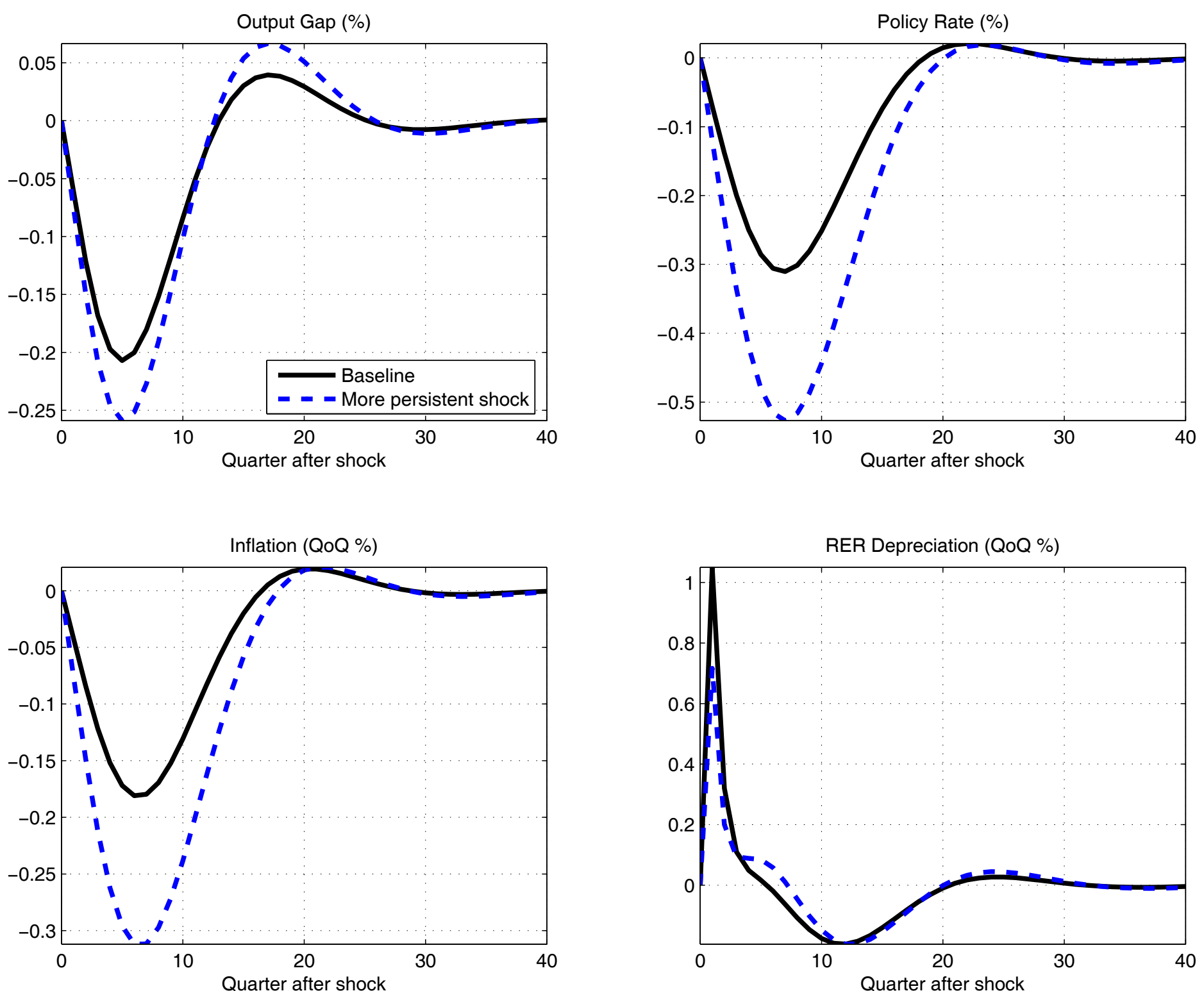

Source: GPM simulation.

CInternational Monetary Fund. Not for Redistribution 
Figure 4. Responses to Euro Area Premium Shock with Stronger Spillover
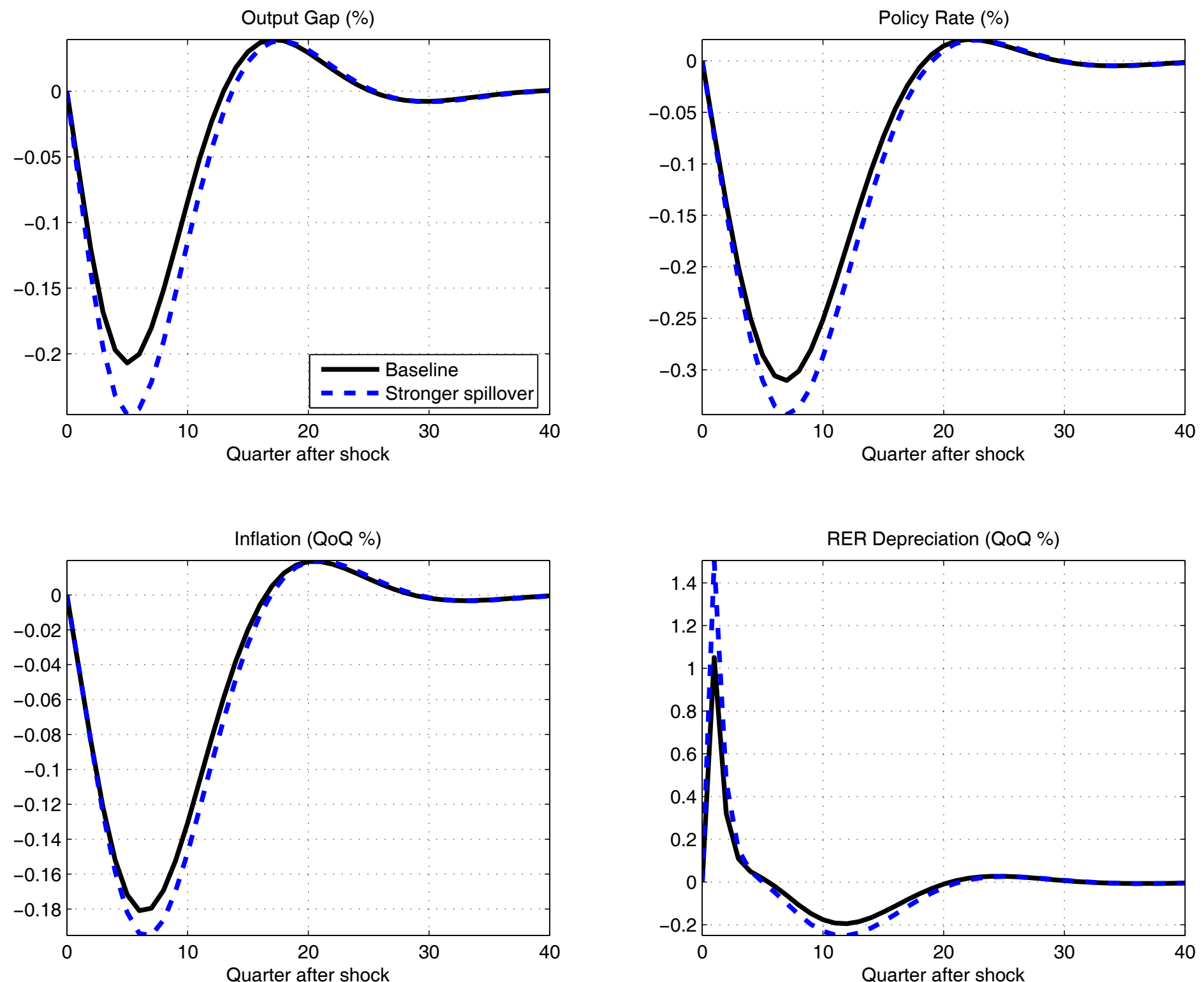

Source: GPM simulation.

CInternational Monetary Fund. Not for Redistribution 


\section{REFERENCES}

Akinci, O. and P. Jeasakul, 2011, "East-West Economic and Financial Linkages in Europe," Chapter 4, October 2011 Regional Economic Outlook: Europe, pp. 83-101.

Andrle, M., C. Freedman, R. Garcia-Saltos, D. Hermawan, D. Laxton, and H. Munandar, 2009, "Adding Indonesia to the Global Projection Model," IMF Working Paper 09/253.

Baxter, M. and M. Crucini, 1995, "Business Cycle and the Asset Structure of Foreign Trade," International Economic Review, Vol. 36, No. 4, pp. 821-54.

Bayoumi, T. and A. Swiston, 2007, "Foreign Entanglements: Estimating the Source and Size of Spillovers Across Industrial Countries," IMF Working Paper 07/182.

Bems, R., R. Johnson, and Kei-Mu Yi, 2010, "Demand Spillovers and the Collapse of Trade in the Global Recession," IMF Economic Review, Vol. 58, No. 2, pp. 295-326.

Benes, J., K. Clinton, R. Garcia-Saltos, M. Johnson, D. Laxton, P. Manchev, and T. Matheson, 2010, "Estimating Potential Output with a Multivariate Filter," IMF Working Paper 10/285.

Bernanke, B., M. Gertler, and S. Gilchrist, 1999, "The Financial Accelerator in a Quantitative Business Cycle Framework," Handbook of Macroeconomics, Vol. 1, Ch. 21, pp. 1341-93.

Carabenciov, I., C. Freedman, R. Garcia-Saltos, D. Laxton, O. Kamenik, and P. Manchev, 2012, "GPM6-The Global Projection Model with Six Regions," forthcoming IMF Working Paper.

Christiano, L., R. Motto, and M. Rostagno, 2010, "Financial Factors in Economic Fluctuations," ECB Working Paper 1192.

Di Giovanni, J. and A. Levchenko, 2009, "Putting the Parts Together: Trade, Vertical Linkages, and Business Cycle Comovement," IMF Working Paper 09/181.

Enders, Z., R. Kollmann, and G. Muller, 2011, "Global Banking and International Business Cycles," European Economic Review, Vol. 55, No. 3, pp. 407-26.

Epstein, N., 2011, "Inflation Forecasting in Poland: A Global Projection Model Approach," Republic of Poland Selected Issues Paper.

Frankel, J. and A. Rose, 1998, "The Endogeneity of the Optimum Currency Area Criteria," Economic Journal, Vol. 108, No. 449, pp. 1009-25. 
Helbling, T., P. Berezin, A. Kose, M. Kumhof, D. Laxton, and N. Spatafora, 2007, "Decoupling the Train? Spillovers and Cycles in the Global Economy," Chapter 4, World Economic Outlook, pp. 121-60.

Hummels, D., J. Ishii, and K. Yi, 2001, "The Nature and Growth of Vertical Specialization in World Trade," Journal of International Economics, No. 54, pp. 75-96.

Kose, A., C. Otrok, and E. Prasad, 2008, "Global Business Cycles: Convergence or Decoupling,” IMF Working Paper 08/143.

Strategy, Policy, and Review Department, 2011, "Changing Patterns of Global Trade."

Swiston, A. and T. Bayoumi, 2008, "Spillovers Across NAFTA," IMF Working Paper 08/3. 


\section{What Drives the Spread Between the POlOnia And the Policy Rate?}

\section{A. Introduction}

\section{Poland has based its monetary policy on inflation targeting (IT) since 1998.} Under IT, the National Bank of Poland (NBP) pursues monetary policy through the interest rate channel to influence the level of aggregate output and inflation. To make the monetary policy framework more effective, the zloty began to freely float in 2000, after the currency peg to a currency composite of euro and U.S. dollar was gradually abandoned. The current inflation target is 2.5 percent with a tolerance band for symmetrical deviations of one percentage point.

\section{The NBP implements monetary policy by conducting open market operations} (OMOs). These OMOs aim to keep the Polish Overnight Index Average (POLONIA), i.e., transaction value-weighted overnight interbank rate, in close proximity to the NBP's policy rate. The NBP's ability to influence the POLONIA rate is an initial step in the monetary policy transmission mechanism, as it can transmit the monetary policy signal to the cost of funding for banks and lending rates. The main instrument for OMOs is the seven-day NBP bill issued every Friday, for which the reference rate is the policy rate. The interest rates on Lombard credit and the NBP's deposit facility determine the corridor for the POLONIA. The NBP's choice of using the overnight POLONIA to replace the Warsaw Interbank Offered Rate Spot Week (WIBOR SW) as the operating target in 2008 was a response to the increasing concentration of overnight maturity of interbank activities, and the POLONIA's being able to represent the true price of liquidity as it is transaction-based.

3. This paper explores determinants of the spread between the POLONIA and the policy rate, or the "POLONIA spread". Since the start of the 2008-09 financial crisis, the spread has persistently been below the policy rate, suggesting a limited influence of the NBP's OMOs on the short-term interbank rate. This may alter the effectiveness of the monetary policy transmission mechanism. In this regard, we analyze the behavior of the POLONIA spread over the period January 2008-December 2011, which includes the 2008 financial crisis and extends into the ongoing euro area crisis. This timeframe also provides a unique opportunity to gauge the effectiveness of the NBP's responses to the financial crisis. In addition, given the Polish banking system's strong linkages with global financial institutions, it is interesting to test whether external factors spill over to the Polish interbank market.

4. The paper is organized as follows. Section $B$ describes the behavior of the POLONIA and POLONIA spread. Section C introduces factors that may influence the

\footnotetext{
${ }^{1}$ Prepared by Yinqiu Lu (EUR).
} 
POLONIA spread. Section D introduces an empirical model to estimate the impact of these factors on the spread. Section E concludes.

\section{B. POLONIA and its Deviation From the Policy Rate}

\section{The POLONIA has closely followed the tightening and easing cycles of the} monetary policies. As expected, the POLONIA moves within the corridor set up by the standing deposit facility and Lombard credit.

6. However, since 2009, the POLONIA has often stayed below the policy rate and has done so persistently. ${ }^{2}$ The mean of the spread can be characterized by an autoregressive process. There are also clear signs of volatility clustering, with significant persistence in the squared spread.

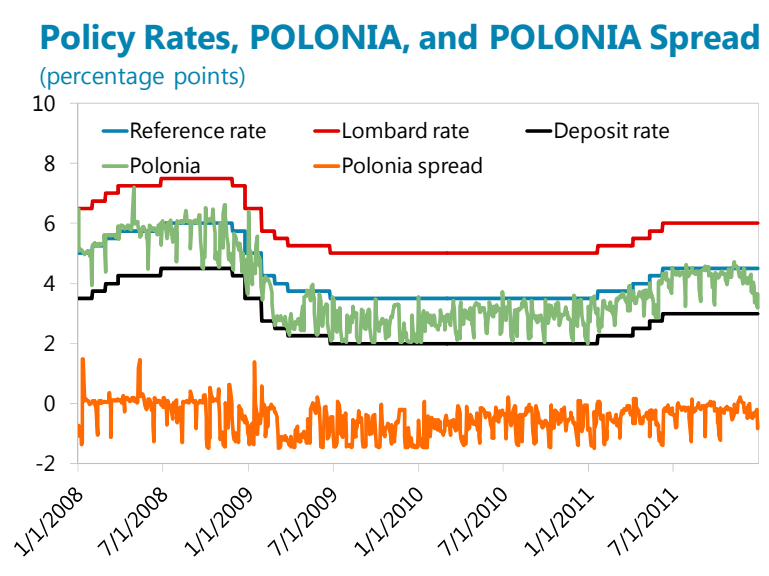

Sources: NBP; Reuters; and IMF staff estimates.

\section{Persistence of the Spread-Autocorrelation Function}

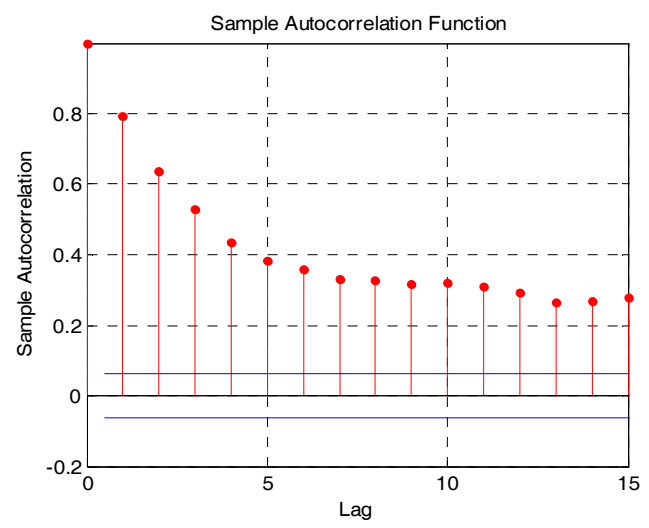

Sources: Reuters; and IMF staff estimates. Note: with +/- 2 standard deviation band.

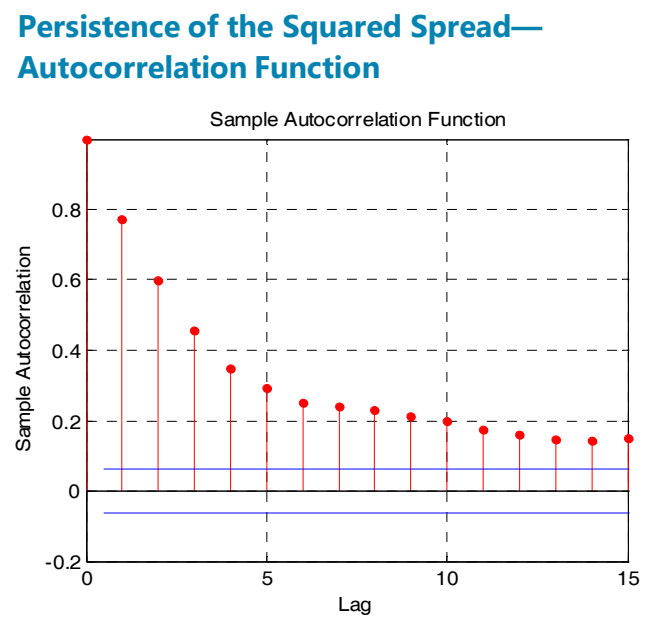

Sources: Reuters; and IMF staff estimates. Note: with +/- 2 standard deviation band.

\footnotetext{
${ }^{2}$ There were ten, four, and 22 days of positive spreads in 2009, 2010, and 2011 respectively.
} 
7. Using a GARCH model, ${ }^{3}$ we can calculate the long-run mean and variance of the POLONIA spread. The long-run mean of the spread is -0.32 percentage points and the variance is 0.46 . The persistence of the variance is 0.92 , which means that following an episode of high volatility, it is expected to remain high.

\section{Determinants of the POLONIA Spread: Predictions}

\section{In this section, we explore several potential determinants of the POLONIA} spread and predict their influence on the spread. The interaction of liquidity supply and demand determines the liquidity situation in the interbank market and hence the POLONIA spread. The NBP's liquidity injection and withdrawal operations influence liquidity supply in the interbank market. Banks' refinancing needs determine liquidity demand. External factors and the structure of the interbank market can also affect the direction and movement of the POLONIA spread.

\section{Liquidity supply}

9. There is a structural liquidity surplus in the banking system.

Measured by autonomous factors (defined as those beyond the control of the central bank in the very short run), Poland's structural liquidity surplus ${ }^{4}$ has increased by 3.5 times since it adopted IT. The increase has been more pronounced since 2009, with the main contributing factor being the accumulation of net foreign assets (NFA), which is a result of the NBP's purchase of foreign exchange (FX) associated with inflows of EU funds and Eurobond issuance receipts from the Ministry of Finance (MOF). To sterilize these FX inflows, the NBP expanded its OMOs by issuing a larger amount of
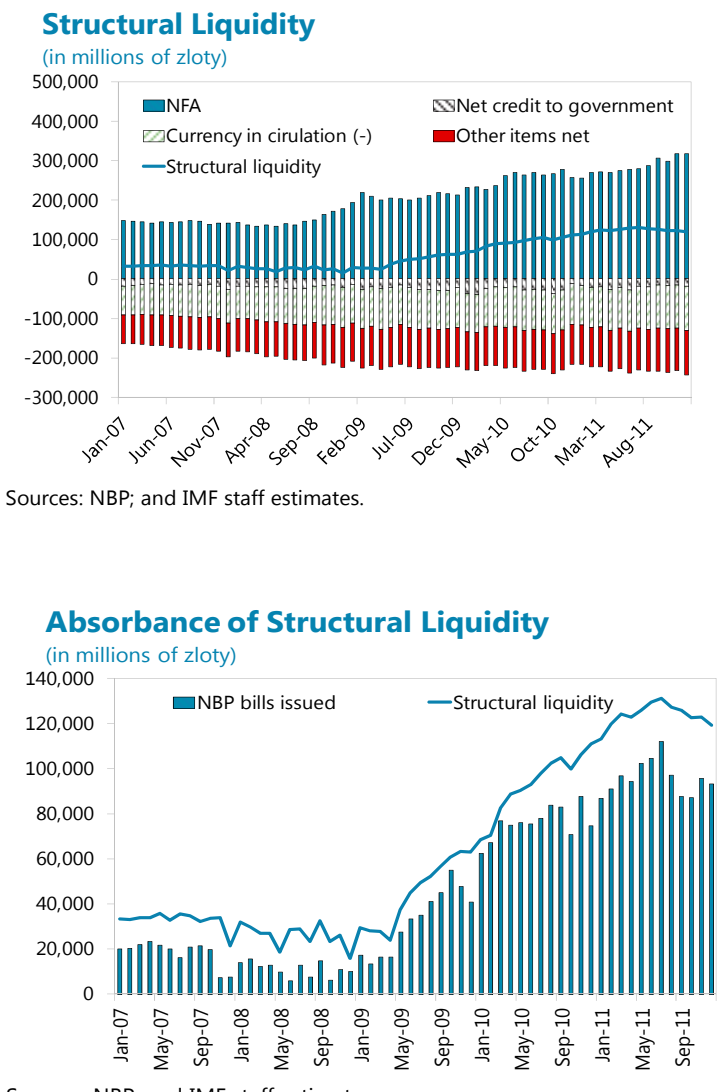
seven-day NBP bills each Friday.

\footnotetext{
${ }^{3}$ Following the empirical model in Panigirtzoglou and others (2000), the spread between the POLONIA and policy rate $\left(s_{t}\right)$ can be modeled as: $s_{t}-s_{t-1}=\alpha_{1}+\alpha_{2} s_{t-1}+\varepsilon_{t} ; E\left(\varepsilon_{t}^{2}\right)=\sigma_{t}^{2}=\beta_{1}+\beta_{2} \varepsilon_{t-1}^{2}+$ $\beta 3 \sigma t-12$, with the long-run mean $=(-\alpha 1 / \alpha 2)$; the persistence of the variance $=\beta 2+\beta 3$, where the variance is explosive if the value is greater than one; and, if $\beta_{2}+\beta_{3}<1$, the variance $=\frac{\beta_{1}}{1-\left(\beta_{2+} \beta_{3}\right)}$.

${ }^{4}$ Structural liquidity $=$ NBP net foreign assets + net credit to government-currency in circulation + other items net. See Appendix I for a more detailed explanation.
} 
10. The NBP's FX purchases increase structural liquidity in the interbank market. There are liquidity injections into the banking system following NBP's FX purchases from the MOF and the corresponding MOF's zloty withdrawal from the NBP, particularly in the case of purchases occurring between two Fridays of OMOs. Since May 2011, the MOF has, at times, converted EU funds on the FX spot market, which does not influence structural liquidity. Recently, the MoF has indicated that it will (at least partly) abandon its practice of converting EU funds in the market, which would increase structural liquidity once again. Regarding the influence on the spread, we expect that the NBP's FX purchases will cause the spread to widen if it is negative and to narrow if it is positive. The influence on the volatility is difficult to predict.

\section{The NBP conducts fine-tuning operations to absorb liquidity in the interbank} market. Two short-term fine-tuning operations were introduced in December 2010, followed by more such operations in 2011. Moreover, since June 2011, the NBP has started to conduct regular fine-tuning operations at the end of the reserve maintenance period by selling one-day NBP bills for banks to deposit extra funds. Our hypothesis is that these operations, particularly the regular ones, should help to narrow the negative spread and dampen its volatility.

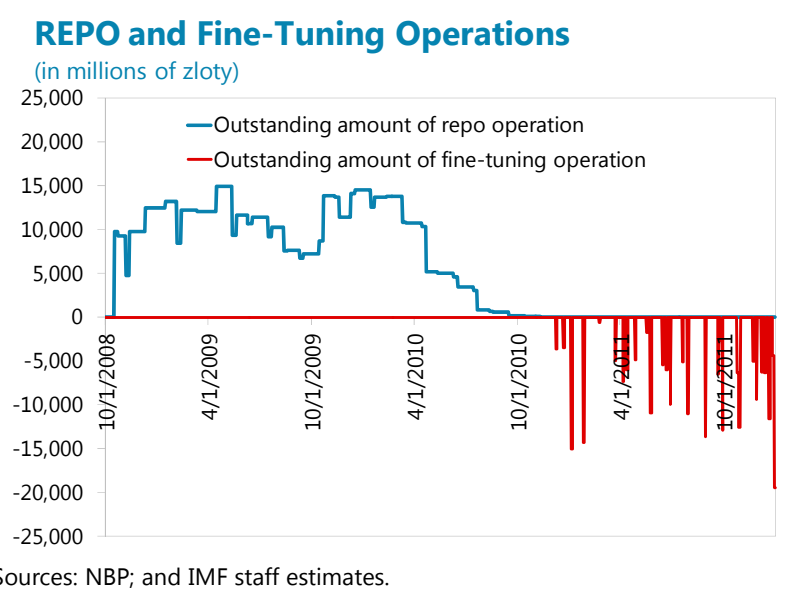

\section{Repo operations initiated by the NBP inject liquidity into the interbank market.}

They were initiated as part of the "Confidence Pact" that was introduced after the collapse of Lehman Brothers. Six repo operations were conducted in 2008 with maturities ranging from six days to three months, and six-month repo operations were added in May 2009. Both the three-month and six-month repo operations were conducted once a month with transaction dates pre-announced. As the liquidity situation eased and demand dried up, six-month repo operations were discontinued in April 2010 and three-month repo operations discontinued in October 2010. Therefore, currently there are no more repo operations. We expect that the repo operations would narrow the positive spread and dampen volatility. They may cause the spread to widen if the spread is negative.

\section{Liquidity demand}

\section{Banks' liquidity demand and participation in OMOs affects the POLONIA} spread. When the market is calm and the NBP is able to project liquidity demand with reasonable accuracy, the allotment of NBP bills is met by demand from banks. However, when there is a liquidity problem or a perceived problem in the interbank market, the NBP faces difficulties in projecting liquidity demand as the demand for NBP bills is weaker. In 
these circumstances, banks prefer to manage liquidity position on an overnight basis rather than locking up liquidity in seven-day NBP bills. Indeed, in the wake of the collapse of Lehman Brothers, the NBP stopped announcing the allotment amount and let the market demand determine the amount, and when the market calmed down, it changed back to its usual practice in February 2009. To a lesser degree, during 2011, banks preferred to have a liquidity cushion and a majority of auctions were underbid (i.e., demand was less than supply). Our

Demand/Supply Ratio of NBP Bill Auctions

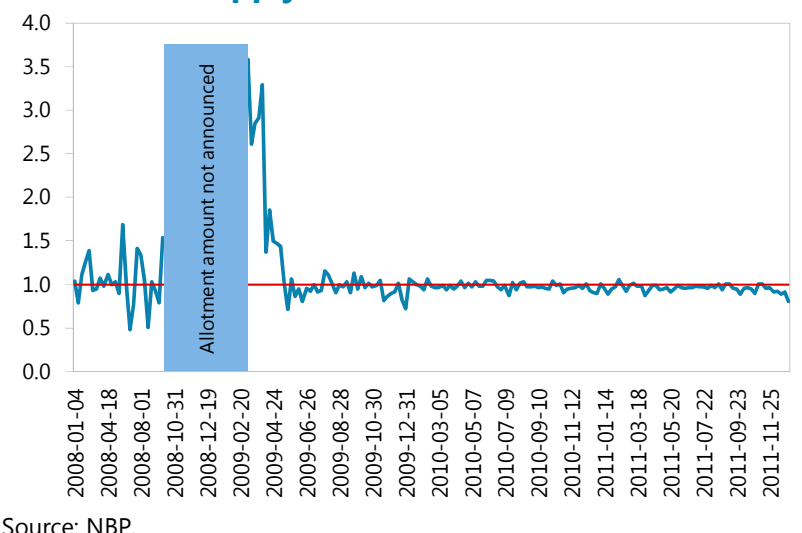

hypothesis is that underbidding should be associated with a wider negative spread, as a lower than expected liquidity surplus reinforces relatively abundant liquidity conditions. The impact on spread volatility is difficult to gauge.

\section{The demand for liquidity is also affected by banks frontloading their fulfillment}

of the reserve requirement. The reserve maintenance period in Poland is one month, starting on the last day of each month and ending on the day before the last day of the following month. On a daily basis, banks' deposits at the NBP can deviate from the reserve requirement, as long as banks' monthly average deposits meet the requirement. This averaging of the reserve requirement gives banks some flexibility in conducting liquidity management. At the start of the reserve maintenance period, banks, being conservative, tend to hold excess reserves. Towards the end of the maintenance period, banks deposit excess funds in the interbank market or use NBP's standing deposit facility to gain interest income.

\section{This frontloading behavior reduces the POLONIA rate and increases its} volatility toward the end of the maintenance period. At the beginning of the maintenance period, banks' frontloading tightens the liquidity situation-a smaller negative spread or a larger positive spread can be observed. At the end of the maintenance period, as excess liquidity is released, the POLONIA sinks further below the policy rate. These maintenance period effects are documented in interbank market literature (Perez Quiros and Mendizabal (2006) and Prati et. al. (2001)). The recently introduced regular fine-tuning operations at the end of maintenance period seem to

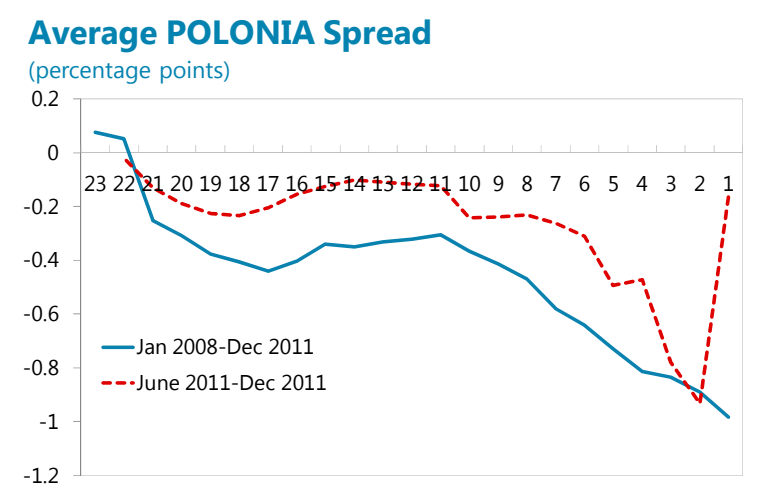

Sources: Reuters; and IMF staff estimates.

Note: the $x$-axis represents the number of days until the next reserve maintenance period. 
have brought the POLONIA significantly closer to the policy rate for the last few days of the reserve maintenance period. We expect that the frontloading behavior is associated with the increasingly negative spread and higher volatility towards the end of the maintenance period.

\section{External factors}

\section{Given the Polish banking} system's close linkages to the euro area banking system, external factors such as global liquidity and market sentiment may influence the interbank market. ${ }^{5}$ Foreign-owned banks and branches - with parents based mostly in the euro area-account for about 65 percent of the Polish banking system. BIS consolidated data shows that foreign banks' claims on Poland amounted to 59 percent of GDP at end-2011. Foreign financial institutions are also important counterparties in foreign currency derivative transactions in which Polish banks are engaged. Therefore, global market sentiment can influence the spread. For example, when market sentiment drove up the EURIBOR-OIS 3-month spread, the interbank market in Poland became tighter.

\section{Structure of the interbank market}

\section{The functioning of Poland's} interbank money market has been impaired by the crises. Transaction volumes in the unsecured interbank market peaked at end-2007. However, turnover subsequently fell sharply, as during the 2008-09 financial crisis banks were hoarding liquidity and cutting interbank credit limits, often set by parent banks. Volumes subsequently

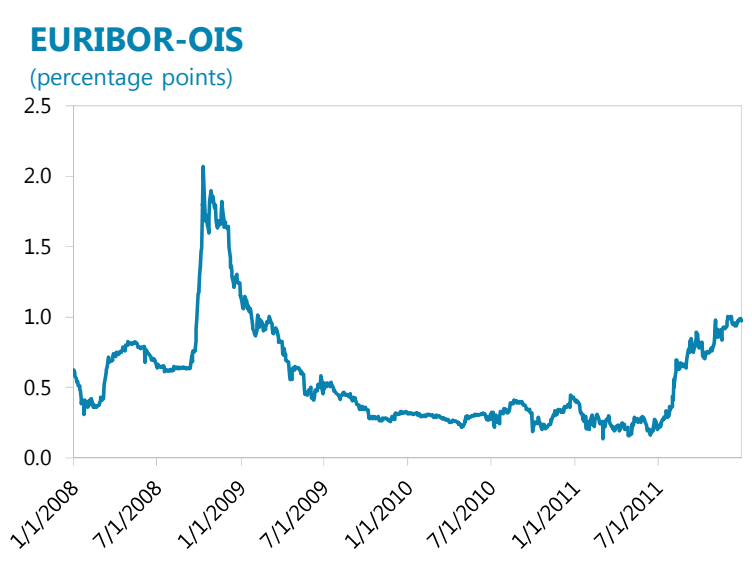

Sources: Bloomberg; and Reuters.

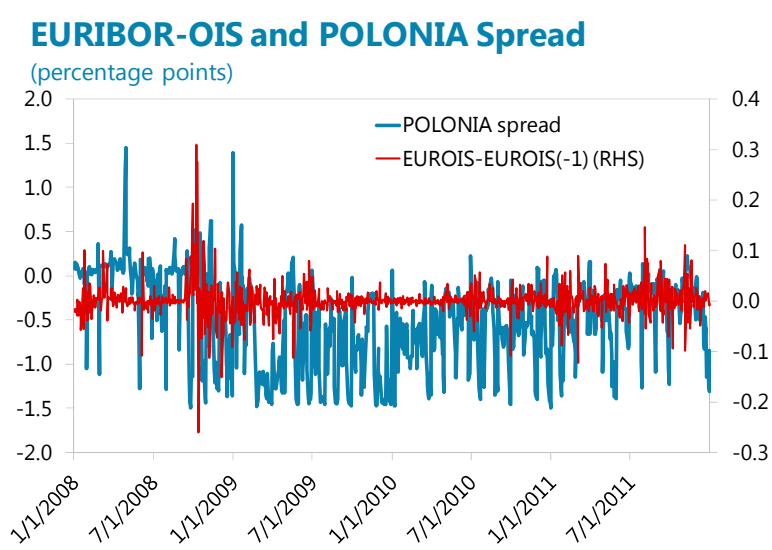

Sources: Bloomberg; Reuters; and IMF staff estimates.

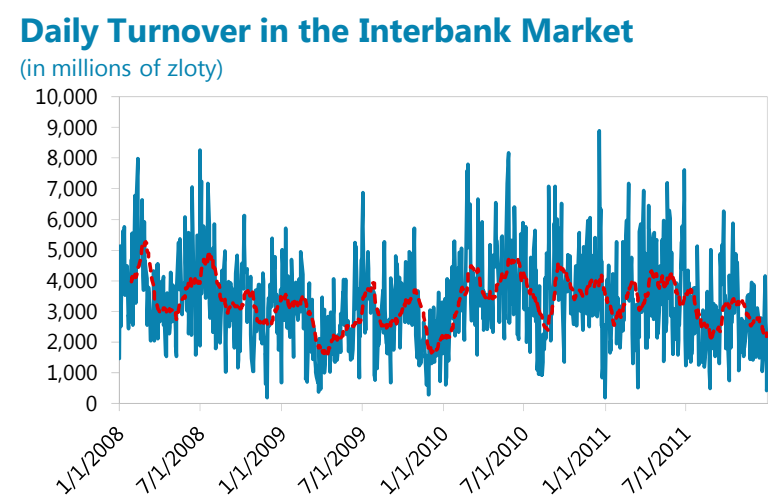

Sources: Reuters; and IMF staff estimates.

Note: Turnover data is based on the calculation for POLONIA rate. The dotted line is the 20 day moving average of the POLONIA turnover.

\footnotetext{
${ }^{5}$ See the Selected Issues Paper, Economic and Financial Linkages with the Euro Area.
} 
recovered before falling again as the euro area crisis intensified. Overnight lending currently accounts for about 90 percent of trading, with little activity beyond one week. Risk-averse banks choose to place their liquidity with the NBP instead of in the interbank market when risks increase. For example, a sharp increase in excess reserves deposited at the NBP was observed at end-2008: the end of year effect was magnified by the collapse of Lehman Brothers and the 3-month WIBOR-OIS spread (a measure of interbank credit risk) widened considerably.

\section{Poland's interbank repo market} remains underdeveloped, with trading volumes half the size of the unsecured interbank market. The liquidity of the government securities market has not been transferred to the liquidity of the repo market. The several billion zloty daily turnover in the interbank repo market is dwarfed by the average daily turnover of 24 billion zloty in the secondary market for treasury securities The lack of a widely-accepted master agreement, a lack of clarity in the terminologies between repo and sellbuy-back/buy-sell-back, and tax regulation that disadvantages repo transactions are the main factors that inhibit the market development. ${ }^{6}$

\section{The overnight nature of the}

\section{unsecured interbank market and banks' limited reliance on repos for liquidity} management have impaired the functioning of the interbank market. When facing short-term funding gaps, banks have to raise deposit rates to compete for deposits as they

\footnotetext{
${ }^{6}$ National Bank of Poland (2007).
} 
cannot rely on the interbank market to meet short-term funding gaps. For example, in November-December 2008, retail deposit rates at many banks increased from 4 percent to over 7 percent, as liquidity conditions tightened. We use the 3-month WIBOR-OIS spread to measure credit risk in the interbank market. Our hypothesis is that higher credit risk could lead to a wider negative spread as banks choose to hoard liquidity. At the same, higher credit risk could lead banks to charge higher rate for interbank borrowing, leading to an increase in the POLONIA rate.

20. The table below summarizes the predictions of the impact of the determinants on the spread.

Table 1. Predictions of the Impact of the Determinants

\begin{tabular}{llcc}
\hline & Determinants & Level & Volatility \\
\hline Liquidity supply & FX purchase & - & $+/-$ \\
& Fine-tuning operations & + & - \\
& Repo operations & - & - \\
Liquidity demand & Underbidding & - & $+/-$ \\
& Frontloading & - & + \\
External factor & Market tightening & + & + \\
Interbank market & Credit risk & $+/-$ & + \\
\hline
\end{tabular}

\section{Empirical Analysis}

21. In this section, an empirical analysis is performed to evaluate the predications we have made in the previous section. The sample data consists of daily observations covering the period from January 2008 to December 2011. In total, we have 1,014 observations of the POLONIA spread.

\section{We model the spread using an exponential GARCH (EGARCH) model.}

EGARCH allows for rich specifications for both the time-varying mean, as well as the time-varying variance of the endogenous variable. In addition, it allows for the variance of positive and negative shocks to differ. Such a model has been used to examine interbank markets in several developed economies where the central bank targets a short-term interbank rate for monetary policy purposes (Bartolini and Prati, 2003; Moschitz, 2004; Prati et. al., 2001). Porter and Xu (2009) applied the EGARCH model to estimate the seven-day repo rate in China's interbank market. 


\section{Our empirical model of the spread is}

with

$$
s_{t}=\sum_{i=1}^{n} \phi_{i} s_{t-i}+\beta_{m} X_{t}^{m}+\sigma_{t} v_{t}
$$

$$
\ln \left(\sigma_{t}^{2}\right)=\varpi+\sum_{j=1}^{q} \gamma_{j} \ln \left(\sigma_{t-j}^{2}\right)+\sum_{i=1}^{p} \alpha_{i}\left|\frac{v_{t-i}}{\sigma_{t-i}}\right|+\sum_{k=1}^{r} \lambda_{k} \frac{v_{t-k}}{\sigma_{t-k}}+\beta_{v} X_{t}^{v} .
$$

The first equation is the mean equation, in which $s_{t}$ is the POLONIA spread, i.e., POLONIA minus policy rate; $\phi_{i}$ is the autoregressive term incorporating the persistence of the spread; $\beta_{m} X_{t}^{m}$ reflects the impact of exogenous factors on the spread; $\sigma_{t}$ is the standard deviation; and $v_{t}$ is the error term. In the second equation-conditional variance equation- $\varpi$ is the constant term; $\gamma_{i}$ is the GARCH term; $\alpha_{i}$ is the ARCH effects; and $\lambda_{k}$ shows the asymmetric impact of positive or negative innovation to the standardized residuals. If $\lambda_{k} \neq 0$, the impact will be asymmetric. $\beta_{v} X_{t}^{v}$ measures the impact of exogenous factors on volatility. Given the apparent "fat tails" exhibited by the spread, we assume that the error term follows a Student's t-distribution.

\section{Exogenous variables include the determinants of the POLONIA spread}

discussed above. For liquidity supply, the dates that the NBP purchased FX from the MOF are set as dummies. The dummies for both the dates that the NBP conducted regular fine-tuning operations and other ad-hoc fine-tuning operations are included. To capture the impact of repo operations, we include both the start dates and settlement dates of the operations as dummies. Usually settlements were completed two days after the start of repo operations. Regarding liquidity demand, dummies for the occurrences of NBP bill underbidding and overbidding are included. The dummies for the last several days of the reserve maintenance period are included as well. We also introduce the change in the EURIBOR-OIS spread - a proxy for the euro interbank market stress - to measure whether it has any impact on the spread. We use the change in the 3-month WIBOR-OIS spread to measure the credit risk in the interbank market. We use the same exogenous variables for the mean and volatility equations to analyze their impact on the level and volatility of the POLONIA spread.

\section{The "general-to-specific" methodology is used to choose the lags of endogenous} and exogenous variables and ARCH and GARCH effects. The GARCH model we choose is the $\operatorname{GARCH}(3,4)$. Most of the variables become statistically insignificant after one lag. Regarding how many days constitute the last few days of the maintenance period, there is no consensus in the literature. We start from Day 1 (the last day of the maintenance period) and include day dummies that are statistically significant in at least one of the two equations and exclude the dummies that are irrelevant in both equations and dummies thereafter. Based on this method, we include dummies from Day 1 to Day 8. 
Table 2. Variables in the Mean and Volatility Equations

\begin{tabular}{|c|c|c|}
\hline & Meaning & Variable Index \\
\hline \multirow[t]{8}{*}{ Liquidity supply } & Dummies for NBP's FX purchase when the spread is positive & Buy_P \\
\hline & Dummies for NBP's FX purchase when the spread is negative & Buy_N \\
\hline & Dummies for the regular fine tuning operations & DRFT \\
\hline & Dummies for the more ad-hoc fine tuning operations & DOFT \\
\hline & $\begin{array}{l}\text { Dummies for the settlement days of repo operations and its lag } \\
\text { when the spread is positive }\end{array}$ & SREPO_P \\
\hline & $\begin{array}{l}\text { Dummies for the start days of repo operations and its lag when the } \\
\text { spread is positive }\end{array}$ & DREPO_P \\
\hline & $\begin{array}{l}\text { Dummies for the settlement days of repo operations and its lag } \\
\text { when the spread is negative }\end{array}$ & SREPO_N \\
\hline & $\begin{array}{l}\text { Dummies for the start days of repo operations and its lag when the } \\
\text { spread is negative }\end{array}$ & DREPO_N \\
\hline \multirow[t]{3}{*}{ Liquidity demand } & Dummies for the overbidding & $\mathrm{D} / \mathrm{S}>=1$ \\
\hline & Dummies for the underbidding & $\mathrm{D} / \mathrm{S}<1$ \\
\hline & Dummies for the last 8 days of reserve maintenance period & D1-D8 \\
\hline External factor & EURIBOR-OIS minus EURIBOR-OIS(-1) & EUROIS-EUROIS(-1) \\
\hline Interbank market & WIBOR-OIS minus WIBOR-OIS(-1) & WIBOIS-WIBOIS(-1) \\
\hline
\end{tabular}

\section{Empirical Results}

26. There are a few general observations. The spread is persistent as there is a large response to the previous day's spread. Given that the variables other than the lag of spread have an impact on the spread, the martingale hypothesis that the interest rate tomorrow should equal to today's expected level for tomorrow in the absence of market frictions (i.e., $i_{t}-E_{t}\left(i_{t+1}\right)=0$ ) does not hold in the case of POLONIA. ${ }^{7}$ In addition, volatility clustering is confirmed with significant GARCH effects. The ARCH effect is significant, while the asymmetric term is not significant.

27. The estimates confirm the extent of fat tails in the spread. The estimated degrees of freedom for the error term are only 2.6, meaning that the innovation is far noisier than implied by a normal distribution. Such low degrees of freedom are normal in estimating interest rates (see Prati et. al., 2001 and Porter and Xu, 2009).

\section{For the mean equation, the impact of the identified determinants on the spread are as follows:}

- $\quad$ Liquidity supply. NBP's purchases of FX from the MOF widen the spread when the spread is negative, which is consistent with our hypothesis. When the spread is positive, the impact of these purchases on the spread is insignificant.

\footnotetext{
${ }^{7}$ See Hamilton (1996).
} 
- Liquidity operations. Fine-tuning operations seem to be successful in reducing the negative spread, particularly in the case of the regular fine-tuning operations introduced recently. The repo operations reduce the spread when the spread is positive, in line with our expectation. When the spread is negative, their impact on the spread is relatively small. Among all the factors, fine-tuning operations (which withdraw liquidity), in particular the regular

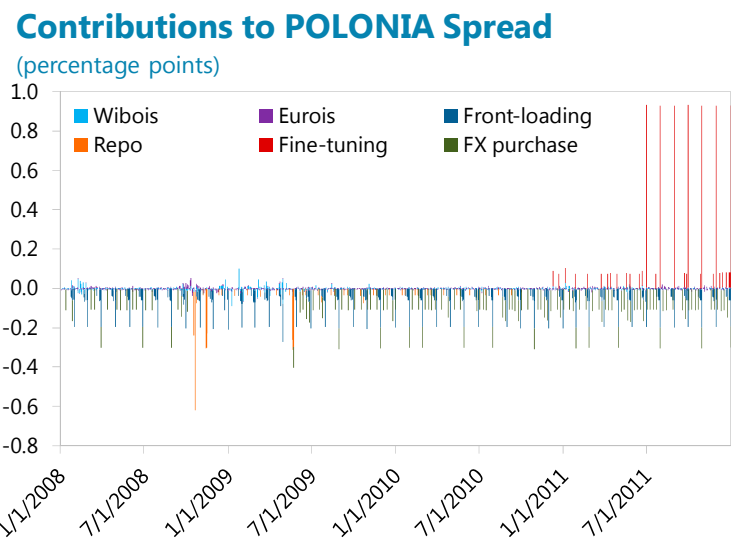
Source: IMF staff estimates. ones, have the largest impact on narrowing the spread if it is negative and widening the spread if positive. Repo operations (which inject liquidity) have the largest impact in the opposite direction.

- $\quad$ Liquidity demand. As expected, the occurrence of underbidding is associated with a widening of the spread if the spread is negative or a narrowing of the spread if it is positive. Most of the dummies for the days of the reserve maintenance period have negative coefficients, meaning that at the end of maintenance period (particularly on the last day) the POLONIA tends to move further below the policy rate. This is consistent with banks' frontloading reserve requirements.

- External factor. The increasing stress in the euro interbank market seems to have led to the tightening of liquidity in the interbank market.

- Interbank market. An increase in interbank credit risk is associated with a widening of the spread if the spread is negative or a narrowing of the spread if it is positive. Therefore, it seems that banks' response to increased credit risk is to hoard liquidity and avoid trading in the interbank market. This is consistent with the increase in the frequency of negative POLONIA spread since the 2008-09 financial crisis.

\section{For the variance equation, the impact of the identified determinants are as}

\section{follows:}

- $\quad$ Liquidity supply. When the spread is positive, the NBP's FX purchases from the MOF tend to reduce volatility. But, when the spread is negative, the impact of FX purchases on the volatility is insignificant. 
- $\quad$ Liquidity operations. Regular fine-tuning operations decrease the volatility of the spread, while, to a lesser extent, the non-regular ones increase the volatility. These operations have the largest impact among all the factors in dam ping spread volatility. Repo operations are associated with higher volatility, particularly when the spread is negative.
Contributions to Log of Variance

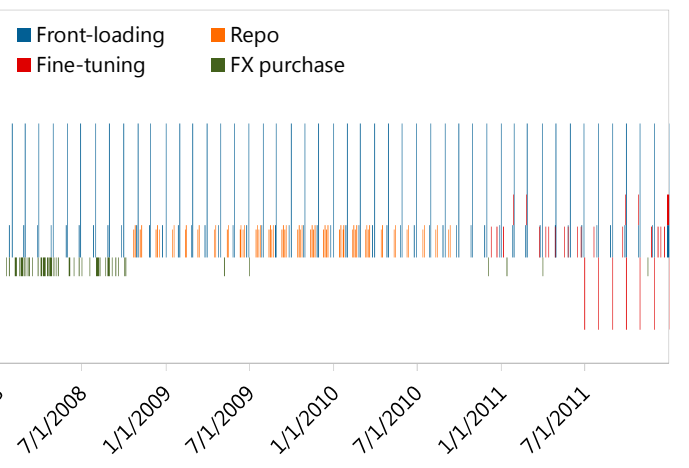

Source: IMF staff estimates.

- $\quad$ Liquidity demand. Volatility of the spread rises under both underbidding and overbidding auctions, likely associated with some market uncertainty during OMOs. Like their impact on the mean of the spread, most of the dummies for the last days of the reserve maintenance period are associated with higher volatility, especially the last day. The impact of frontloading on heightening volatility is the highest among all the factors. This high volatility is consistent with other analyses (see Prati et. al., 2001).

- External factor. The change of the EURIBOR-OIS spread does not have an impact on volatility.

- Interbank market. An increase in interbank credit risk does not have an impact on volatility.

\section{E. Conclusion and Policy Implications}

\section{This paper analyzes the behavior and determinants of the POLONIA spread} between January 2008 and December 2011. A persistently negative POLONIA spread since 2009 is observed. This is related to the existence of structural liquidity in the banking system and banks' unwillingness to lock up liquidity in the seven-day NBP bills. The frontloading of banks' fulfillment of the reserve requirements also plays a role, particularly during the last few days of the maintenance period. In addition, external market sentiment also has some influence on the spread.

\section{The NBP's response to the fluid liquidity situation has been effective. The repo} operations initiated as a response to the financial crisis have played a positive role in steering the POLONIA towards the policy rate. The liquidity-absorbing fine-tuning operations seem to be successful in reducing both the level and volatility of the POLONIA spread, particularly in the case of the regular fine-tuning operations introduced recently. However, the persistently negative spread may have weakened the monetary policy transmission mechanism. 
32. It is challenging to keep the POLONIA close to the policy rate. Some factors are out of the control of the NBP, such as external environment, which needs to be stable to reduce banks' incentive to hoard liquidity. Nevertheless, the NBP could have more influence on other factors. In the short term, the NBP should be provided with enough information to forecast liquidity as accurately as possible. To facilitate this, greater coordination between the MoF and the NBP is needed: it is important for the NBP to have advanced information regarding MOF's anticipated exchanges of foreign currency inflows into zloty. In addition, the NBP could assess its instruments for liquidity management on regular basis, and, if needed, introduce new instruments on a trial basis to gauge market demand and expectation (e.g., the newly introduced fine-tuning operations) and assess their impact on interbank market activity. In the medium to long term, enhancing the activities of interbank market and developing long-term local currency funding could help banks to conduct better asset and liability management, a conduit for the improvement of the monetary policy transmission mechanism. 
Table 3. Estimated GARCH Parameters

Dependent variable: Spread

Included observations: 1,013 after adjustments

\begin{tabular}{|c|c|c|c|c|}
\hline \multicolumn{5}{|l|}{ Mean equation } \\
\hline Variable & Coefficient & Std. Error & z-Statistic & $p$ value \\
\hline SPREAD(-1) & 0.972 & 0.007 & 131.518 & 0.000 \\
\hline BUY_P & 0.011 & 0.009 & 1.250 & 0.211 \\
\hline BUY_N & -0.028 & 0.008 & -3.335 & 0.001 \\
\hline DRFT_EX & 0.928 & 0.109 & 8.483 & 0.000 \\
\hline DOFT_UNEX & 0.076 & 0.031 & 2.432 & 0.015 \\
\hline SREPO_P & -0.222 & 0.076 & -2.919 & 0.004 \\
\hline SREPO_P(-1) & -0.298 & 0.164 & -1.822 & 0.068 \\
\hline DREPO_P & -0.070 & 0.070 & -1.003 & 0.316 \\
\hline DREPO_P(-1) & -0.305 & 0.047 & -6.524 & 0.000 \\
\hline SREPO_N & -0.019 & 0.020 & -0.935 & 0.350 \\
\hline SREPO_N(-1) & 0.062 & 0.039 & 1.597 & 0.110 \\
\hline DREPO_N & 0.000 & 0.021 & -0.019 & 0.985 \\
\hline DREPO_N(-1) & -0.032 & 0.015 & -2.173 & 0.030 \\
\hline $\mathrm{D} / \mathrm{S}>=1$ & 0.016 & 0.014 & 1.199 & 0.230 \\
\hline$D / S<1$ & -0.106 & 0.013 & -8.216 & 0.000 \\
\hline D1 & -0.195 & 0.089 & -2.205 & 0.027 \\
\hline D2 & -0.057 & 0.017 & -3.356 & 0.001 \\
\hline D3 & -0.037 & 0.026 & -1.419 & 0.156 \\
\hline D4 & -0.058 & 0.018 & -3.268 & 0.001 \\
\hline D5 & -0.042 & 0.017 & -2.516 & 0.012 \\
\hline D6 & -0.016 & 0.020 & -0.820 & 0.412 \\
\hline D7 & -0.037 & 0.014 & -2.568 & 0.010 \\
\hline D8 & -0.012 & 0.014 & -0.869 & 0.385 \\
\hline EUROIS-EUROIS(-1) & 0.145 & 0.074 & 1.964 & 0.050 \\
\hline WIBOIS-WIBOIS(-1) & -0.096 & 0.028 & -3.398 & 0.001 \\
\hline \multicolumn{5}{|l|}{ Variance Equation } \\
\hline C_var & -1.983 & 0.181 & -10.967 & 0.000 \\
\hline ABS(RESID(-1)/SQRT(GARCH(-1)) & 0.688 & 0.151 & 4.545 & 0.000 \\
\hline ABS(RESID(-2)/SQRT(GARCH(-2)) & -0.246 & 0.128 & -1.923 & 0.054 \\
\hline ABS(RESID(-3)/SQRT(GARCH(-3)) & 0.300 & 0.109 & 2.755 & 0.006 \\
\hline RESID(-1)/SQRT(GARCH(-1)) & 0.025 & 0.056 & 0.447 & 0.655 \\
\hline LN(GARCH(-1)) & 1.162 & 0.077 & 15.078 & 0.000 \\
\hline $\mathrm{LN}(\mathrm{GARCH}(-2))$ & -0.920 & 0.123 & -7.477 & 0.000 \\
\hline LN(GARCH(-3)) & 0.532 & 0.114 & 4.657 & 0.000 \\
\hline LN(GARCH(-4)) & -0.111 & 0.065 & -1.719 & 0.086 \\
\hline BUY_P & -0.531 & 0.181 & -2.933 & 0.003 \\
\hline BUY_N & 0.155 & 0.110 & 1.406 & 0.160 \\
\hline DRFT_EX & -2.055 & 0.681 & -3.019 & 0.003 \\
\hline DOFT_UNEX & 0.866 & 0.384 & 2.255 & 0.024 \\
\hline SREPO_P & -1.081 & 2.469 & -0.438 & 0.662 \\
\hline SREPO_P(-1) & 2.532 & 1.716 & 1.476 & 0.140 \\
\hline DREPO_P & -0.958 & 2.290 & -0.418 & 0.676 \\
\hline DREPO_P(-1) & 0.893 & 3.143 & 0.284 & 0.776 \\
\hline SREPO_N & 0.784 & 0.482 & 1.625 & 0.104 \\
\hline SREPO_N(-1) & 0.912 & 0.415 & 2.198 & 0.028 \\
\hline DREPO_N & 0.792 & 0.344 & 2.302 & 0.021 \\
\hline DREPO_N(-1) & -0.389 & 0.456 & -0.854 & 0.393 \\
\hline $\mathrm{D} / \mathrm{S}>=1$ & 0.868 & 0.211 & 4.113 & 0.000 \\
\hline$D / S<1$ & 1.158 & 0.180 & 6.431 & 0.000 \\
\hline D1 & 3.784 & 0.390 & 9.693 & 0.000 \\
\hline D2 & -0.472 & 0.456 & -1.035 & 0.301 \\
\hline D3 & 0.823 & 0.545 & 1.509 & 0.131 \\
\hline D4 & 0.915 & 0.521 & 1.758 & 0.079 \\
\hline D5 & -0.063 & 0.537 & -0.118 & 0.906 \\
\hline D6 & 0.712 & 0.522 & 1.363 & 0.173 \\
\hline D7 & 0.199 & 0.464 & 0.428 & 0.669 \\
\hline D8 & 0.398 & 0.328 & 1.215 & 0.225 \\
\hline EUROIS-EUROIS(-1) & -1.704 & 1.585 & -1.075 & 0.282 \\
\hline WIBOIS-WIBOIS(-1) & 0.147 & 0.482 & 0.305 & 0.760 \\
\hline T-DIST. DOF & 2.625 & 0.301 & 8.720 & 0.000 \\
\hline R-squared & 0.644 & & & \\
\hline Adjusted R-squared & 0.635 & & & \\
\hline S.E. of regression & 0.309 & & & \\
\hline Sum squared resid & 94.359 & & & \\
\hline Log likelihood & 374.157 & & & \\
\hline Durbin-Watson stat & 2.153 & & & \\
\hline Mean dependent var & -0.495 & & & \\
\hline S.D. dependent var & 0.512 & & & \\
\hline Akaike info criterion & -0.622 & & & \\
\hline Schwarz criterion & -0.336 & & & \\
\hline Hannan-Quinn criter. & -0.513 & & & \\
\hline
\end{tabular}

CInternational Monetary Fund. Not for Redistribution 


\section{REFERENCES}

Bartolini, Leonardo, and Alessandro Prati, 2003, "Cross-Country Differences in Monetary Policy Execution and Money Market Rates' Volatility," FRB of New York Staff Report No. 175 (New York: Federal Reserve Bank of New York).

Hamilton, James D., 1996, “The Daily Market for Federal Funds,” Journal of Political Economy, Vol. 104, No. 1, pp. 26-56 (Chicago, Illinois: University of Chicago Press).

Moschitz, Julius, 2004, "The Determinants of the Overnight Interest Rate in the Euro Area," European Central Bank Working Paper No. 393 (Frankfurt: European Central Bank).

National Bank of Poland, 2007, "Financial System Development in Poland 2007."

Panigirtzoglou, Nikolaos, James Proudman, and John Spicer, 2000, "Persistence and Volatility in Short-Term Interest Rates," Bank of England Working Paper No. 116.

Perez Quiros, Gabriel, and Hugo Rodriguez Mendizabal, 2006, “The Daily Market for Funds in Europe," Journal of Money, Credit and Banking, Vol. 38, No. 1, pp. 91-118 (Columbus, Ohio: The Ohio State University).

Porter, Nathan, and TengTeng Xu, 2009, “What Drives China's Interbank Market?” IMF Working Paper 09/189 (Washington: International Monetary Fund).

Prati, Alessandro, Leonardo Bartolini, and Guiseppe Bertola, 2001, "The Overnight Interbank Market: Evidence from the G-7 and the Euro Zone," FRB of New York Staff Report No. 135 (New York: Federal Reserve Bank of New York). 


\section{Appendix I. Structural Liquidity}

This appendix defines structural liquidity and its components. Structural liquidity refers to the aggregate liquidity position of the banking system, which corresponds to the sum of autonomous factors that are beyond the control of the central bank in the very short run.

The supply of liquidity through autonomous factors can be derived from a simplified balance sheet of the central bank. By netting the external position of the central bank and the position against the government, and summarizing all other assets and liabilities (other items, net), a simplified balance sheet is shown as follows:

\begin{tabular}{ll}
\multicolumn{2}{c}{ A Simplified Balance Sheet of the Central Bank } \\
\hline Assets & Liabilities \\
\hline$>$ Net foreign assets & $>$ Currency in circulation \\
$>$ Net credit to government & $>$ Minimum reserve requirements (MRR) \\
$>$ Lending to banks/OMOs & $>$ Excess reserves \\
$>$ Other items, net & \\
\hline
\end{tabular}

\section{Accordingly, factors influencing the liquidity supply can be derived as:}

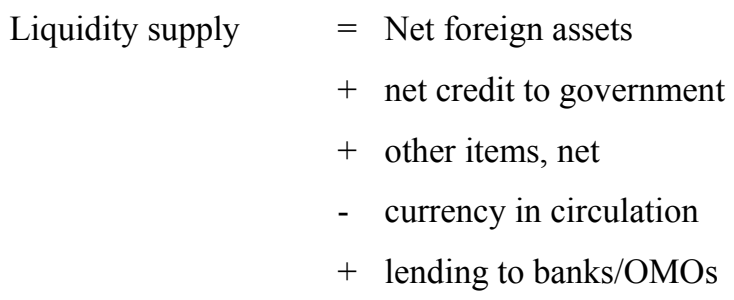

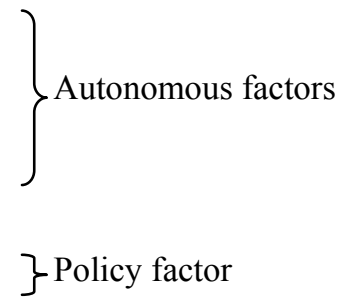

\} Policy factor

Three situations related to structural liquidity are possible. When the structural liquidity exceeds the MRR, the banking system has a structural liquidity surplus with respect to the central bank, meaning that it does not need to obtain funding from the central bank. Instead, the central bank may conduct OMOs to absorb surplus liquidity from the banking system. Poland's banking system is currently in a structural liquidity surplus position. When the structural liquidity is exceeded by the MRR, the banking system has an aggregate liquidity deficit with respect to the central bank, and lending to banks by the central bank may be needed to relieve the liquidity shortage. The third case is a balanced structural liquidity position, which means structural liquidity is equal to the MRR. 